\title{
Biomethane Yield, Physicochemical Structures, and Microbial Community Characteristics of Corn Stover Pretreated by Urea Combined with Mild Temperature Hydrotherm
}

\author{
Yao Lu ${ }^{1}$, Hairong Yuan ${ }^{1}$, Xiaoyu Zuo ${ }^{1}{ }^{1}$, Yanqing Chang ${ }^{2}$ and Xiujin $\mathrm{Li}^{1, *}$ \\ 1 Beijing Engineering Center for Pollution Control and Resource Recovery, Beijing University of Chemical \\ Technology, Beijing 100029, China; luyao@mail.buct.edu.cn (Y.L.); yuanhairong75@163.com (H.Y.); \\ zuoxy@mail.buct.edu.cn (X.Z.) \\ 2 WELLE Environmental Group Co., Ltd., Changzhou 213125, China; changyanqing@wellegroup.com \\ * Correspondence: xjli@mail.buct.edu.cn
}

check for updates

Citation: Lu, Y.; Yuan, H.; Zuo, X.; Chang, Y.; Li, X. Biomethane Yield, Physicochemical Structures, and Microbial Community Characteristics of Corn Stover Pretreated by Urea Combined with Mild Temperature Hydrotherm. Polymers 2021, 13, 2207. https://doi.org/10.3390/

polym13132207

Academic Editor: $\mathrm{Hu} \mathrm{Li}$

Received: 6 June 2021

Accepted: 29 June 2021

Published: 3 July 2021

Publisher's Note: MDPI stays neutral with regard to jurisdictional claims in published maps and institutional affiliations.

Copyright: (c) 2021 by the authors. Licensee MDPI, Basel, Switzerland. This article is an open access article distributed under the terms and conditions of the Creative Commons Attribution (CC BY) license (https:/ / creativecommons.org/licenses/by/ $4.0 /)$.

\begin{abstract}
The corn stover (CS)'s compact structure makes it challenging for microorganisms to use in anaerobic digestion (AD). Therefore, improving CS biodegradability has become a key focus in AD studies. Methods are being targeted at the pretreatment of CS, combining advanced urea with mild temperature hydrotherm pretreatment to study its effect on promoting the AD process of CS. The biomethane yield, physicochemical structure, and microbial community characteristics were investigated. CS samples were assigned into groups differed by a range of pretreatment times (from 24 to $96 \mathrm{~h}$ ) and set at a temperature of $50{ }^{\circ} \mathrm{C}$ with a $\%$ urea addition. Results revealed that the $72-\mathrm{h}$ group obtained the highest biomethane yield of $205 \mathrm{~mL} / \mathrm{g} \mathrm{VS}^{-1}$, volatile solid (VS) and total solid (TS) removal rates of $69.3 \%$ and $47.7 \%$, which were $36.7 \%, 25.3 \%$ and $27.5 \%$ higher than those of untreated one, respectively. After conducting several analyses, results confirmed the pretreatment as a method for altering CS microstructures benefits biomethane production. The most resounding differences between pretreated and untreated groups were observed within a microbial community, an integral factor for improved AD performance. This study serves to confirm that this specific pretreatment is an effective method for enhancing biomethane production in CS.
\end{abstract}

Keywords: anaerobic digestion; pretreatment; urea; hydrothermal; whole slurry; microbial community

\section{Introduction}

China is the second-largest energy consumer in the world. With total energy consumption on a steady rise as their economy continues to develop. According to statistics, China's total energy consumption reached 4870 million tonnes in 2019 based on standard coal [1]. Meanwhile, China is also one of the largest agricultural export countries, responsible for a considerable portion of global crop production. Corn is one of three major crops in China, with corn production reaching 260.8 million tonnes in 2019. This production directly results in a sizeable 344.2 million tonnes of corn stover (CS), consisting of the leaves, stalks and cobs of the plant leftover after harvest [1]. Although CS is frequently reused in various ways, large amounts are either abandoned or burned in open fields, contributing to resource waste and polluting the air [2].

Only a few technologies have been developed for CS treatment and reuse, including animal feed, fertiliser or direct combustion to generate electricity [3-5]. One of these technologies, anaerobic digestion (AD), has garnered significant attention in recent years. When compared to other available technologies, AD has several advantages, such as mitigating waste pollution, producing clean bioenergy and reuse as organic fertiliser. Approximately 70 billion $\mathrm{m}^{3}$ of biomethane can be produced annually if all the CS in China were converted through AD technology. This amount would account for $22.8 \%$ of total natural gas consumption-or 43.4\% of all imported natural gas—in China for 2019 [1]. In this way, AD technology can play an important role in providing clean bioenergy for China. 
The main components of CS are cellulose, hemicellulose and lignin, mutually crosslinked to form a complex three-dimensional (3D) structure. This structure is highly resistant to degradation through anaerobic microbes, leading to long digestion time and low biomethane yields. AD technology is not being used widely for industrial-scale bioconversion of lignocellulosic substrates in China. The key challenge is how to improve CS biodegradability to achieve high-efficiency anaerobic digestion (AD).

Pretreatment before the AD process is one of the most effective approaches for improving the biodegradability of lignocellulosic feedstocks such as CS, with numerous studies previously conducted in this area. Generally, pretreatment can be classified into physical, chemical, biological pretreatment, and the combination of them [6]. No matter what method is applied, the basic principle is to destroy the chemical structure, decrease cellulose crystallinity, increase effective surface area and decompose the lignin element. Among these methods, chemical pretreatment is regarded as most effective and is consequently more widely applied. Chemicals commonly used include acids $\left(\mathrm{H}_{2} \mathrm{SO}_{4}, \mathrm{HPO}_{4}\right)$, alkali $\left(\mathrm{NaOH}, \mathrm{KOH}, \mathrm{NH}_{3} \cdot \mathrm{H}_{2} \mathrm{O}, \mathrm{CO}\left(\mathrm{NH}_{2}\right)_{2}\right)$, oxidant agents $\left(\mathrm{H}_{2} \mathrm{O}_{2}, \mathrm{O}_{3}\right)$, organic solvents (ethyl alcohol, methyl alcohol, acetone) and ionic liquids [7,8]. The alkaline pretreatment has been more widely studied with the most proven and trustworthy results. Zheng et al. [9] reported a $72.9 \%$ gas production increase through $\mathrm{NaOH}-$ pretreated $\mathrm{CS}$. He et al. [10] supported this by reporting a $58.1 \%$ improvement on biogas yields from rice straw following a solid-state $\mathrm{NaOH}$ pretreatment. The study further found that ester bonds between lignin and hemicellulose were destroyed, while the functional groups of cellulose, hemicellulose and lignin were only partly degraded after the alkaline hydrolysis reaction, which contributed to the overall improved biodegradability of CS. Unfortunately, excess $\mathrm{Na}^{+}$left in the effluent potentially causes soil salinisation when applied as fertiliser, which greatly limits the application of $\mathrm{NaOH}$ pretreatment. Similar positive pretreatment effects can, however, be achieved with $\mathrm{KOH}$. Jaffar et al. [11] obtained a 45\% higher biogas production with just $6 \% \mathrm{KOH}$-pretreated wheat straw. Although this improvement is a trade-off, as $\mathrm{KOH}$ is expensive and unsuitable for all industrial applications. Yuan et al. [12] stated that ammonia pretreatment could swell and destroy the lignocellulose structure, improving biomethane production. However, ammonia emits a particularly pungent smell and presents challenges for transportation, storage and application of the weak base.

Urea is well known and widely used as a fertilizer, but, little is known on its ability to serve as a pretreatment reagent for lignocellulosic wastes, including for wheat straw, CS, softwood spruce and hardwood birch [13-15]. Compared to other alkaline reagents, using urea has the following advantages: (i) relative cheap price and easy application and use; (ii) as a pretreatment reagent, its nitrogen source assists with adjusting the carbon-to-nitrogen ratio $(\mathrm{C} / \mathrm{N})$ of $\mathrm{CS}$ - which would otherwise be added during the AD process [16] and (iii) increases fertiliser value of $\mathrm{N}$-digestate when added during pretreatment [17]. However, as a weak base, urea is not as strong as $\mathrm{KOH}$ or $\mathrm{NaOH}$, and is consequently not capable of achieving the same enhancement effects [16]. However, the pretreatment effect could be improved by combining urea with various other methods. For instance, CS pretreated with a $1: 1(2 \% w / v)$ urea ratio, combined with $\mathrm{KOH}$ at $30^{\circ} \mathrm{C}$ for $2 \mathrm{~h}$, could obtain a $75.49 \%$ increase in enzymatic digestibility. This combined approach seemingly achieved better results than that of single base-treated CS set to the same pretreatment conditions [18]. Yu et al. [19] reported that urea pretreatment combined with biochar could improve the digestibility of lignocellulosic substrates, while also enhancing the buffer capacity of the AD process.

Hydrothermal pretreatment is another potential method to catalyse CS degradation, which can be used in isolation or together with other methods. A few studies have shown that hydrothermal pretreatment is useful to enhance the effect of alkali pretreatment on lignocellulosic wastes. Sato et al. [20] conducted hydrothermal pretreatment on rice straw with $\mathrm{NaOH}(0-7 \%)$ at $100-200{ }^{\circ} \mathrm{C}$, revealing that more lignin, cellulose and hemicelluloses were solubilised in the process. Song et al. [21] observed that the highest methane yield $\left(188.7 \mathrm{~mL} / \mathrm{g}\right.$ volatile solids $\left.(\mathrm{VS})^{-1}\right)$ was obtained when CS was pretreated with $8 \% \mathrm{NaOH}$ 
at a temperature of $55^{\circ} \mathrm{C}$. However, to date, no specific study has been conducted on the use of urea combined with a mild temperature hydrothermal pretreatment, nor on its effect on biomethane production and corresponding microbial community.

Based on the above analyses, a new pretreatment method combing urea and mild hydrotherm approaches was proposed. Consequently, the objectives of this study are to (1) investigate the effect of the new pretreatment on CS biomethane production and substance bioconversion; (2) reveal the inner mechanisms of this pretreatment by exploring changes in CS microphysical morphology, chemical composition and structure and their influences on $\mathrm{AD}$ performance and (3) to analyse $\mathrm{AD}$ microbial community structures and their effects. This study provided a theoretical basis for future applications of urea combined with mild temperature hydrotherm as a pretreatment for CS to aid in biomethane production.

\section{Material and Methods}

\subsection{Feedstock and Inoculum}

CS was obtained from Yanqing County, Beijing, China. It was naturally air-dried and then crushed to 20 mesh. The inoculum for the AD was taken from a biogas station where pig manure was used as a feedstock in Shunyi District, Beijing, China. Raw material properties used in this study are listed in the supporting information provided in Table S1.

\subsection{Experimental Design}

For better understanding, Figure 1 outlines the process of urea-hydrothermal CS pretreatment, mesophilic AD and all subsequent analyses conducted in this study.

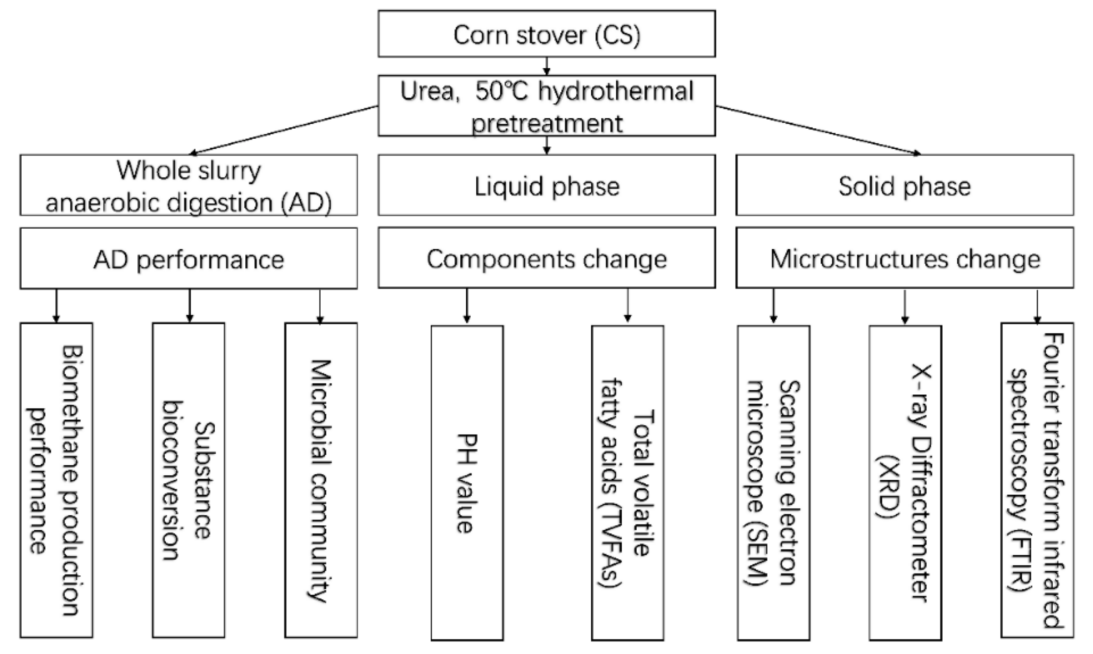

Figure 1. Flow chart of experimental design.

\subsubsection{Pretreatment Methods}

According to preliminary experimental results, $96 \mathrm{~h}$ was chosen as the upper limit for pretreatment time. All CS samples were assigned into groups divided according to a set pretreatment time from 24 to 96 h; these groups were labelled as T24-T96, accordingly. In this experiment, the hydrothermal-urea pretreatment devices were 1-L glass bottles, which were heated in a constant temperature incubator, with the pretreatment temperature set to $50{ }^{\circ} \mathrm{C}$. The CS was added to the 1-L bottles with $2 \%$ urea addition (based on the dry weight of CS) and a solid-to-liquid-i.e., pure water content-ratio of 1:6 [22]. After all materials were rubbed and mixed well, bottles were placed within a constant temperature incubator for 24, 48, 72 and $96 \mathrm{~h}$-i.e., T24, T48, T72 and T96, respectively. When complete, pretreated CS was cooled to room temperature. The leaching liquid of pretreated CS was collected for $\mathrm{pH}$ and total volatile fatty acid (TVFA) content determination. After drying at $60^{\circ} \mathrm{C}$ for $48 \mathrm{~h}$, the solids were stored for subsequent TS/VS degradation rate, Fourier 
transform infrared spectroscopy (FTIR), X-ray diffractometer (XRD) and scanning electron microscope (SEM) characterisation [22].

\subsubsection{Anaerobic Digestion}

The experimental apparatus consisted of $1 \mathrm{~L}$ sealed flask, $1 \mathrm{~L}$ gas collecting bottle, and constant temperature water bath $\left(35 \pm 1^{\circ} \mathrm{C}\right)$. The sealed flask was used to serve as the AD reactor with a working volume of $0.8 \mathrm{~L}$.

For the $\mathrm{AD}$ test, the pretreatment methods used were the same as above. The organic load was $50 \mathrm{~g}$ TS/L. When the pretreatment was complete, each bottle of pretreated CS (whole slurry) was cooled to room temperature and mixed with $15 \mathrm{~g}$ mixed liquor suspended solids (MLSS)/L inoculum [23]. After inoculation, tap water was added to the working volume and readied for a subsequent 50 -day AD test. Untreated CS was settled as a control group. The inoculum group was selected to remove the background biomethane value. All groups were run in triplicate.

The ratio of carbon to nitrogen $(\mathrm{C} / \mathrm{N})$ has a significant effect on microbial activity in the $\mathrm{AD}$ system, resulting in biomethane yields [24]. In this study, calculated $\mathrm{C} / \mathrm{N}$ for the $\mathrm{AD}$ system of all pretreated groups as well as the untreated group were determined at 17 and 24. Therefore, the $\mathrm{C} / \mathrm{N}$ for pretreated groups was lower than the untreated group due to urea addition, which may be lower than the proposed 20-30 [24]. However, all pretreated groups generally performed better in $\mathrm{AD}$ than untreated. This implied that the difference of $\mathrm{C} / \mathrm{N}$ was not the main factor for varying $\mathrm{AD}$ performance in this study.

\subsubsection{Analytical Methods}

Biogas production was measured daily using a water displacement method [25]. Daily biogas production was converted to the volume of gas under standard conditions $(273.15 \mathrm{k}, 101.325 \mathrm{kPa})$. Biogas components $\left(\mathrm{CH}_{4}, \mathrm{H}_{2}, \mathrm{~N}_{2}\right.$ and $\left.\mathrm{CO}_{2}\right)$ were analysed using a gas chromatograph (GC) (GC-2014C, Shimadzu, Kyoto, Japan), equipped with a thermal conductivity detector and a TDX-01 column. The carrier gas used was a high-purity argon with a flow rate of $30 \mathrm{~mL} / \mathrm{min}$. Temperatures of the injector port, oven and detector were set to $150{ }^{\circ} \mathrm{C}, 120^{\circ} \mathrm{C}$ and $150{ }^{\circ} \mathrm{C}$ [23].

The TS and VS. were measured using American Public Health Association standard methods [26]. Ash content was measured by oxidising samples at $575 \pm 5^{\circ} \mathrm{C}$ for $2 \mathrm{~h}$ in a muffle furnace [27]. The $\mathrm{pH}$ was determined using a $\mathrm{pH}$ metre (Mettler Toledo, FiveEasy Plus, Zurich, Switzerland). Total carbon, total hydrogen (TH), total nitrogen (TN) and total oxygen (TO) were measured using an Element Analyser (Vario EL/Microcube, Elementar, Hanau, Germany). The total composition of TVFAs was determined through a GC (GC2014C, Shimadzu, Kyoto, Japan) equipped with a flame ionisation detector (FID). FTIR (Nicolet 6700, Thermo Fisher, Madison, WI, USA) was used to conduct chemical composition analysis of CS through the $\mathrm{KBr}$ compression method, ranging from $500-4000 \mathrm{~cm}^{-1}$. After sputter-coated with gold, an SEM (Hitachi S-4700, Hitachi, Tokyo, Japan) was used to observe and capture images for CS samples [28]. An XRD (D8-Advance, Bruker, Rheinstetten, Germany) was used to determine crystallinity. All CS samples were scanned from $5^{\circ}$ to $90^{\circ}$ at a scanning rate of $5^{\circ} / \mathrm{min}$. The crystallinity index was calculated using Equation (1) [29].

$$
\operatorname{CrI}(\%)=\left[\left(\mathrm{I}_{002}-\mathrm{I}_{\mathrm{am}}\right) / \mathrm{I}_{002}\right] \times 100 \%
$$

$\mathrm{I}_{002}$ is the diffraction intensity of 002 peak at the diffraction angle $2 \theta=22.0$, and $\mathrm{I}_{\mathrm{am}}$ is the diffraction intensity of peak at the diffraction angle $2 \theta=18.0$.

Biodegradability was determined based on the elemental analysis results of raw CS through Equations (2)-(4) [30].

$$
\begin{aligned}
\mathrm{C}_{\mathrm{n}} \mathrm{H}_{\mathrm{a}} \mathrm{O}_{\mathrm{b}} \mathrm{N}_{\mathrm{c}}+ & \left(\mathrm{n}-\frac{\mathrm{a}}{4}-\frac{\mathrm{b}}{2}+\frac{3 \mathrm{c}}{4}\right) \mathrm{H}_{2} \mathrm{O} \\
& \rightarrow\left(\frac{\mathrm{n}}{2}+\frac{\mathrm{a}}{8}-\frac{\mathrm{b}}{4}-\frac{3 \mathrm{c}}{8}\right) \mathrm{CH}_{4}+\left(\frac{\mathrm{n}}{2}-\frac{\mathrm{a}}{8}+\frac{\mathrm{b}}{4}+\frac{3 \mathrm{c}}{8}\right) \mathrm{CO}_{2}+\mathrm{cNH}_{3}
\end{aligned}
$$




$$
\begin{aligned}
\operatorname{EMY}(\mathrm{mL} / \mathrm{gVS}) & =\frac{22.4 \times 1000 \times\left(\frac{\mathrm{n}}{2}+\frac{\mathrm{a}}{8}-\frac{\mathrm{b}}{4}-\frac{3 \mathrm{c}}{8}\right)}{12 \mathrm{n}+\mathrm{a}+16 \mathrm{~b}+14 \mathrm{c}} \\
\mathrm{BD} & =\frac{\mathrm{CMY}}{\mathrm{EMY}} \times 100 \%
\end{aligned}
$$

EMY is the theoretical biomethane yield of the substrate, and CMY is the experimentallyobtained biomethane yield of the substrate.

When the $\mathrm{AD}$ test was complete, the digestate was stored in a $-20^{\circ} \mathrm{C}$-refrigerator for subsequent bacterial and archaeal DNA extraction. A PCR Amplifier (ABI GeneAmp ${ }^{\circledR}$, 9700, ThermoFisher, Waltham, MA, USA) was used for PCR amplification. The primer design for real-time PCR assays is outlined in Table S2. A microbial community test was conducted by a qualified biomedical technology company. Data were analysed on the online platform Majorbio Cloud Platform (www.majorbio.com, accessed on 28 October 2020).

\subsubsection{Data Analysis}

For statistical analysis and diagram drawing, Excel 2019 (Microsoft, Redmond, DC, USA) and Origin Pro 2019 (OriginLab, Northampton, MA, USA) software were applied. SPSS 23.0 (IBM, Armonk, NY, USA) was applied for statistical analysis, using $t$ tests to perform all pairwise comparisons between pretreated and control group ( 0.05 of $p$-value).

\section{Results and Discussion}

\subsection{AD Performance}

3.1.1. Biomethane Production

Daily biomethane production from untreated and pretreated CS is shown in Figure 2a. In general, similar trends of daily biomethane production were observed in all experiment groups, with two peaks appearing during the 50-day AD test. However, the time of first peak and peak value between untreated and pretreated groups were different.

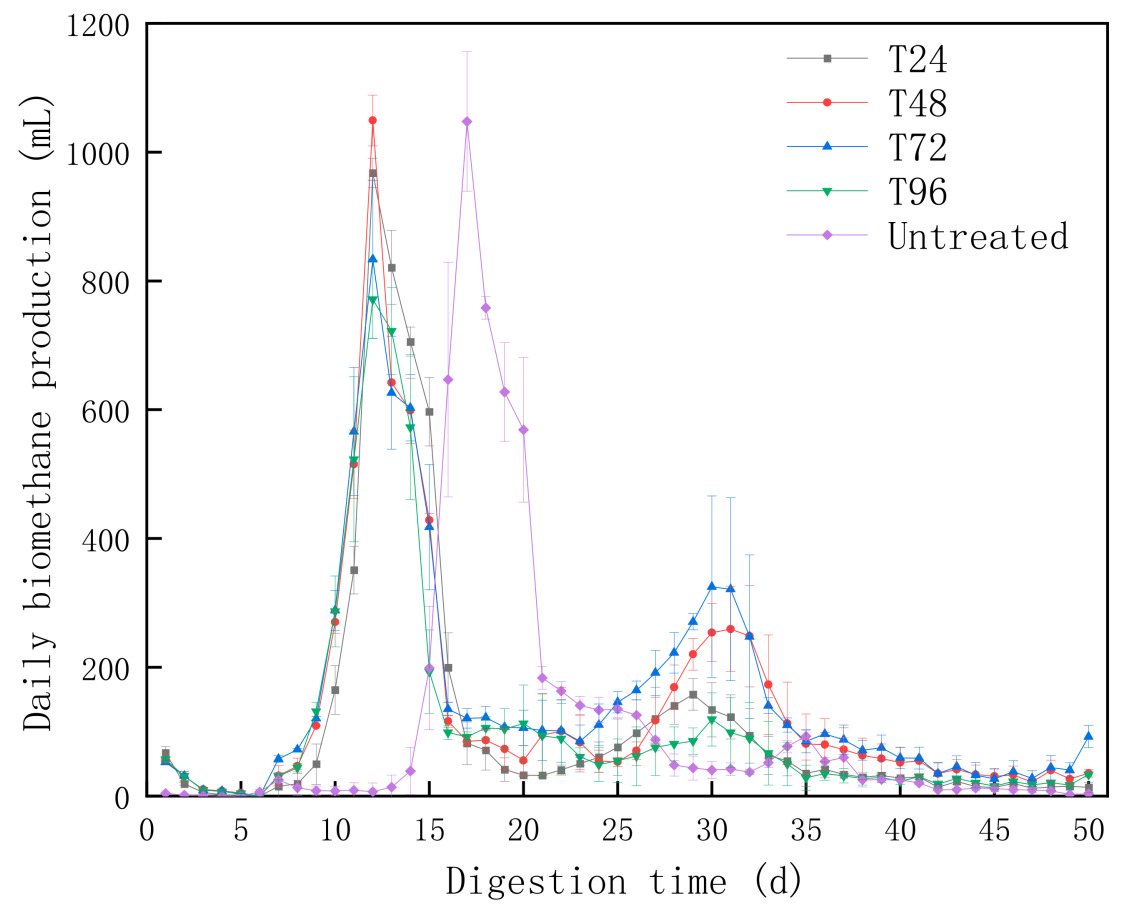

(a)

Figure 2. Cont. 


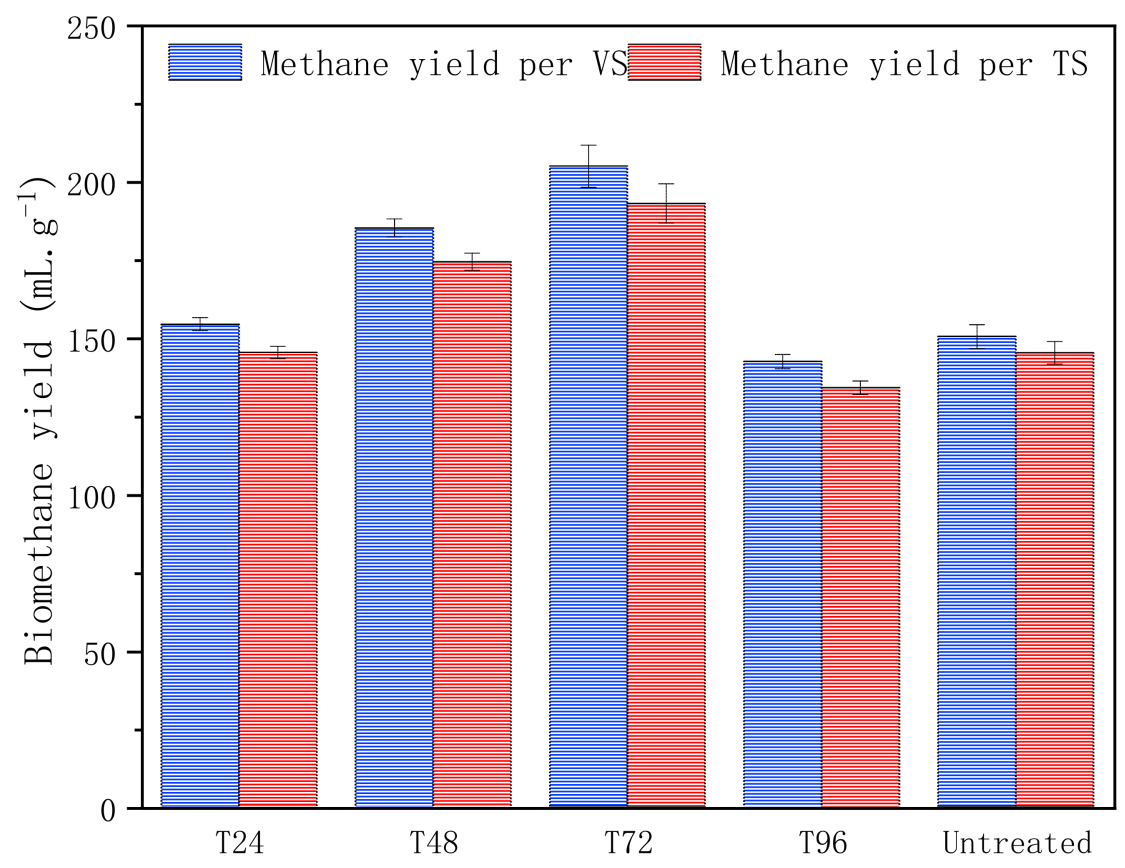

(b)

Figure 2. (a) Daily biomethane productions for pretreated and untreated corn stover; (b) Biomethane yields for pretreated and untreated corn stover.

Daily biomethane production observations were better for all pretreated groups than in untreated groups during the first $48 \mathrm{~h}$. This result revealed that more hydrolysed products were generated from the solid phase of CS and dissolved in the liquid phase after pretreatment, indicating its bioavailability and ability to conduct more biomethane production in the initial AD stage. This observation was consistent with previous studies that highlighted more biodegradable volatile fatty acids (VFAs) and reducing sugars were released into the liquid after hydrothermal pretreatment processes [31].

Among all peaks, the first peak of all pretreated groups-T24, T48, T72 and T96occurred on the 12th day, whereas untreated samples peaked at day 17, approximately 5 days later. In addition, the second peak for all pretreated groups appeared from 29 to 31 days, which was 4-6 days shorter than the untreated group (35 days). This can be attributed to the positive effect of hydrothermal-urea pretreatment on the decomposed CS structure, which was beneficial for efficient $\mathrm{AD}$, hence reflecting that the biodegradability of CS was improved under pretreatment conditions. Furthermore, the pretreatment could peel off the waxy layer on the surface of CS, change the hydrophobic surface structure, improve the biological accessibility and make it easier to be used in microorganism processes. This could be the reason to explain why the first peaks of pretreated samples were 5 days than untreated samples.

As shown in Figure 2a, the daily methane production (DMP) of the first peaks reached $968,1,049,833,771$ and 1,047 mL, with second peaks reaching 158, 260, 325, 119 and $93 \mathrm{~mL}$, for T24, T48, T72, T96 and untreated groups, respectively. The first peak value for T72 and T96 was not as high as T48. It could be explained by the long pretreatment time generating more intermediate products—such as HMF, 4-HMF and phenolics—-that inhibited microbial activity in the bioreactor at the initial stage [32]. However, the daily biomethane production of T72 group exceed T48 group at day 16 and maintained a relatively higher biomethane production until 50 days. Furthermore, the T72 group achieved the highest second peak value ( $325 \mathrm{~mL}$ ), which was $25 \%$ higher than T48 group and nearly $200 \%$ higher than the untreated group. This implies that the biodegradable substances in T72 were more suitable than other groups. The 72-h hydrothermal-urea pretreatment could effectively modify CS 
structures, increase hydrolysis efficiency and produce more substrates for methanogenesis; hence improving total biomethane yield.

Acidification occurred over a long period for both untreated and pretreated groups. The $\mathrm{pH}$ value was lower than 6 , with biomethane production almost stopping entirely and only gradually recovering after $\sim 8$ days for pretreated groups, with a 14-day lag phase (recovery) time for the untreated group. This acidification phenomenon was also observed in other research at the start-up stage of $\mathrm{AD}$ [15]. The main reason for this could be explained as follows. At the beginning of $\mathrm{AD}$, the $\mathrm{CS}$ hydrolysis rate was greater than the biomethane production rate, meaning that a large amount of VFAs could not be used by the methanogens immediately, causing VFA accumulation. Hence, methanogens-particularly acetoclastic methanogenesis - was inhibited by the low $\mathrm{pH}$ [33]. In this study, the shorter acidification recovery time for all pretreated groups suggests that urea addition could improve buffer capacity to some extent, which is beneficial for AD [19].

\subsubsection{Biomethane Yield}

The cumulative biomethane yield from untreated and pretreated CS for different pretreatment times is shown in Figure $2 b$.

The biomethane yield per vs. of the T72 group was highest $\left(205 \mathrm{~mL} / \mathrm{g} \mathrm{VS}^{-1}\right)$, which was $33.1 \%, 10.8 \%, 44.4 \%$ and $36.7 \%$ higher than that of the T24 $\left(154 \mathrm{~mL} / \mathrm{g} \mathrm{VS}^{-1}\right), \mathrm{T} 48$ $\left(185 \mathrm{~mL} / \mathrm{g} \mathrm{VS}^{-1}\right)$, T96 $\left(142 \mathrm{~mL} / \mathrm{g} \mathrm{VS}^{-1}\right)$ and untreated group $\left(150 \mathrm{~mL} / \mathrm{g} \mathrm{VS}^{-1}\right)$, respectively. The 72-h pretreatment time was more efficient in converting CS to biomethane and improved cumulative biomethane production in $\mathrm{AD}$ compared with untreated or other pretreated groups. The biomethane yield per TS revealed a similar trend, with T72 achieving the highest $193 \mathrm{~mL} / \mathrm{g} \mathrm{TS}^{-1}$, which was $33.1 \%, 10.9 \%, 44 \%$ and $33.1 \%$ higher than that of the T24 $\left(145 \mathrm{~mL} / \mathrm{g} \mathrm{TS}^{-1}\right), \mathrm{T} 48\left(174 \mathrm{~mL} / \mathrm{g} \mathrm{TS}^{-1}\right), \mathrm{T} 96\left(134 \mathrm{~mL} / \mathrm{g} \mathrm{TS}^{-1}\right)$ and untreated group $\left(145 \mathrm{~mL} / \mathrm{g} \mathrm{TS}^{-1}\right)$, respectively. The difference in biomethane yields per VS/TS between the T72 and untreated group was significant $(p<0.05)$. This result confirmed that the optimal time for pretreatment is $72 \mathrm{~h}$.

The maximum amount of increase in biomethane yields of the T72 group was similar to the optimal result $\left(20^{\circ} \mathrm{C}, 6\right.$ days of urea pretreatment), which was $45.2 \%$ higher than in untreated CS, as reported by Yao et al. [15]. However, $50^{\circ} \mathrm{C}$ hydrothermal-urea nearly halved the pretreatment time. Thus, the biomethane yield reflected that the 72-h pretreatment increased the efficiency in converting CS into biomethane. Meanwhile, it also indicated that the combination of hydrothermal and urea pretreatment had great potential to shorten the hydraulic retention time in practical AD applications.

\subsubsection{Substance Bioconversion}

The conversion of the volatile solid content of lignocellulosic biomass during AD can be illustrated through the vs. removal rate. It can also be used to compare the efficiency of different pretreatment conditions [12]. These vs. components are used by hydrolytic fermentation and methanogenesis microbes to form intercellular substances and produce biomethane. However, the TS removal rate is not always completely correlated to biomethane yield. vs. removal rate, therefore, is commonly used as an indicator to evaluate substance conversion and biomethane production efficiency in the AD system.

In this study - as shown in Figure 3a-VS removal rates were 56\%, 63.2\%, 69.3\%, 55.2\% and $55.3 \%$ for T24, T48, T72, T96 and untreated groups, respectively. Normally, the higher the vs. removal rate is, the more biomethane is produced. These results showed a trend similar to Bolado et al. [32]. The highest vs. and TS removal rate was T72 group $(69.3 \%$ and $47.7 \%)$, which was $25.3 \%$ and $27.5 \%$ higher than in the untreated group $(p<0.05)$. Meanwhile, the T72 group also had the highest biomethane yield, which was correlated to the maximum vs. removal rate above. 


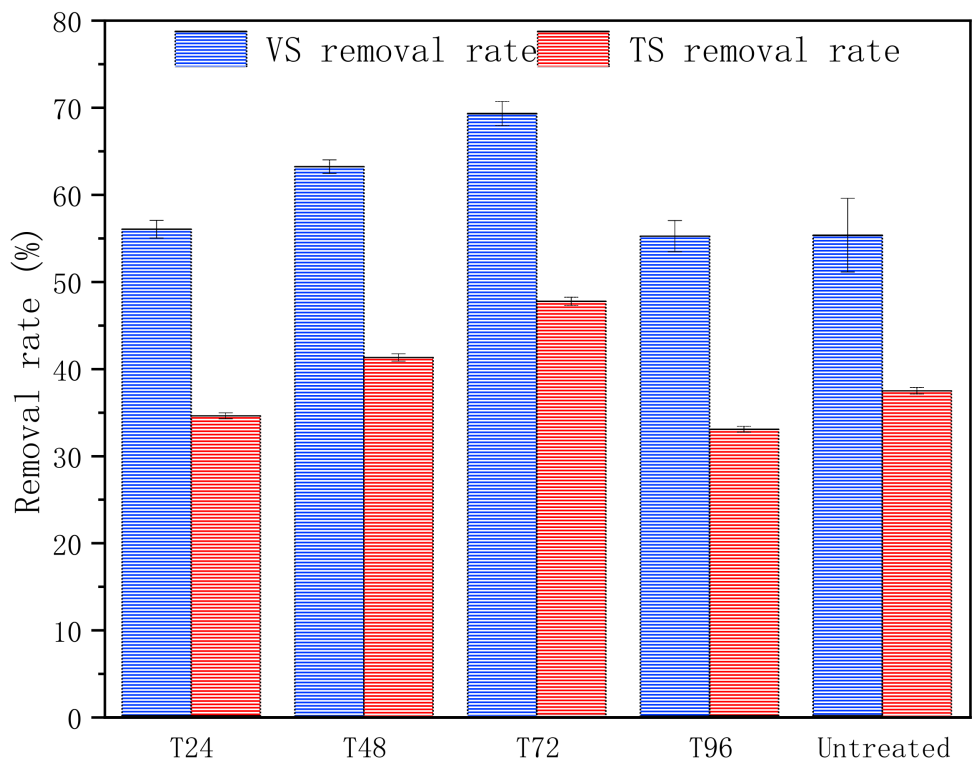

(a)

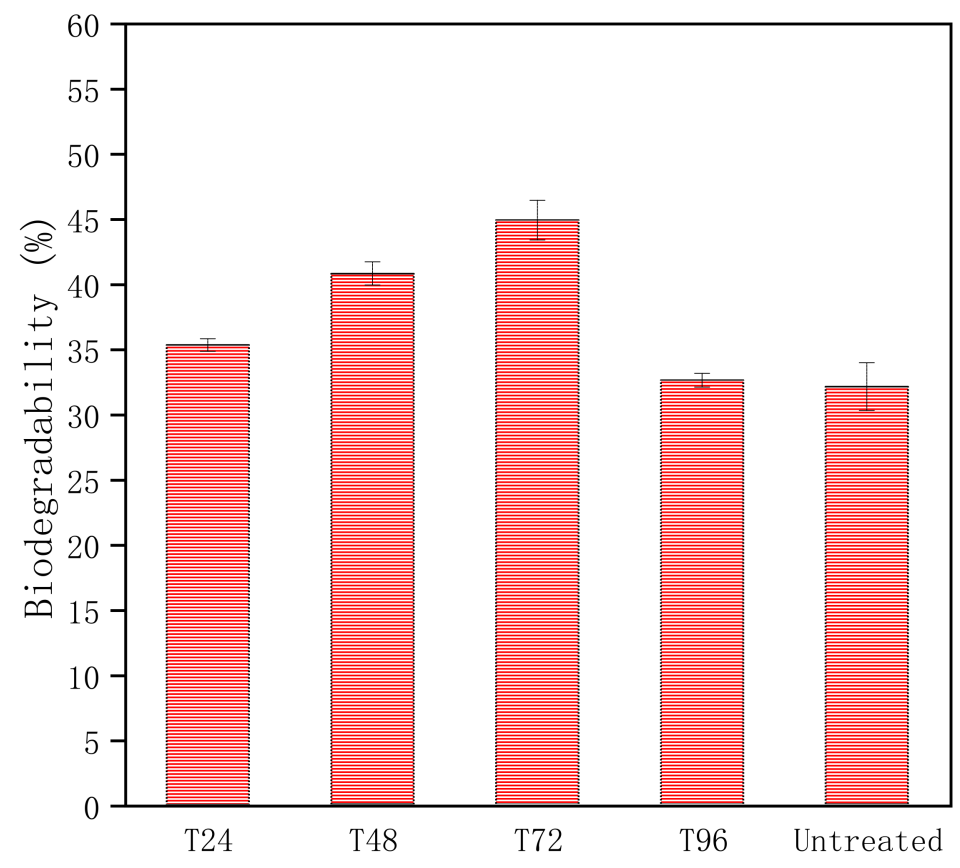

(b)

Figure 3. (a) TS/VS removal rates for pretreated and untreated corn stover; (b) Biodegradability for pretreated and untreated corn stover.

Biodegradability (BD; Figure 3b) is an index used to characterise the conversion efficiency of the organic components of substrates, which in turn reflects the energy conversion efficiency and AD-biodegradable properties. Among the different pretreatment groups, T72 achieved the highest BD (44.9\%), which was 39.8\% higher than the untreated group $(p<0.05)$. This indicated that the biomass energy output and biodegradation performance of the T72 group was better than the untreated group. To summarise, for the same input of CS, more energy would be obtained after a 72-h pretreatment, which reflects the effectiveness of hydrothermal-urea pretreatment for improving CS biodegradability, further enhancing AD biomethane production. 
These results demonstrate that the biodegradability of CS was improved after hydrothermal-urea pretreatment. Additionally, the highest vs. removal rate in the T72 group corresponded to the highest cumulative biomethane yield, which highlighted that the increase of biomethane production was in line with the consumption of more organic substrates. This infers that the bioconversion ability of CS was enhanced, further improving the biomethane production yield under this pretreatment condition.

Generally, with the exception of the T96 group (due to the presence of inhibitors), other pretreated groups showed successful increases in vs. removal rate, BD and biomethane yield. Based on this, the hydrothermal-urea pretreated process was beneficial to CS in the AD process.

\subsection{Pretreatment Mechanism}

To further understand the impact of pretreatment on CS, the pretreatment mechanism was explored from different aspects, including the typical compositional changes, cellulose crystallinity, chemical structure variation, and microstructure deconstruction.

\subsubsection{Total Volatile Fatty Acids (TVFAs)}

Dissolved substances in the pretreatment process have a great impact on subsequent AD. For example, some VFAs components can be used by microorganisms, while alkalisoluble lignin is difficult to be utilised and may inhibit the AD process. Therefore, it is necessary to conduct a further analysis of pretreatment products. In this study, the $\mathrm{pH}$ value and concentration of TVFAs were used to characterise the effect of pretreatment on changing components during the AD process.

The $\mathrm{pH}$ value is always used to assess the effect of pretreatment [34]. Figure 4 shows $\mathrm{pH}$ changes during different pretreatment times. During the pretreatment, the initial $\mathrm{pH}$ of CS dropped rapidly from 6.9 to 5.4 . However, after $24 \mathrm{~h}, \mathrm{pH}$ slowly escalated to 5.9 and stabilised for nearly $24 \mathrm{~h}$, finally settling at a slightly increased 6.3 after $96 \mathrm{~h}$. The trend in $\mathrm{pH}$ changes was similar to the result reported by Li et al. [13]. The reason why $\mathrm{pH}$ value dropped at the initial $24 \mathrm{~h}$ is that the water exhibits acid properties at high temperatures. $\mathrm{H}_{3} \mathrm{O}^{+}$and $\mathrm{OH}^{-}$is dissociated and then acts as catalysts to promote the hydrolysis of lignocellulosic components, breaking the chemical bonds in molecules. Furthermore, the hydrolysis of acetyl dissociated into acids (VFAs), resulting in the decrease of $\mathrm{pH}$ in the medium and further deacetylation and hydrolysis of raw materials [35]. A possible reason for $\mathrm{pH}$ increase after $24 \mathrm{~h}$ could be attributed to the gradual hydrolysis of urea and release of ammonia, which can further dissolve in water and generate $\mathrm{OH}^{-}$. The neutralisation reaction between $\mathrm{OH}^{-}$and VFAs resulted in the $\mathrm{pH}$ increase from $24 \mathrm{~h}$ to $96 \mathrm{~h}$.

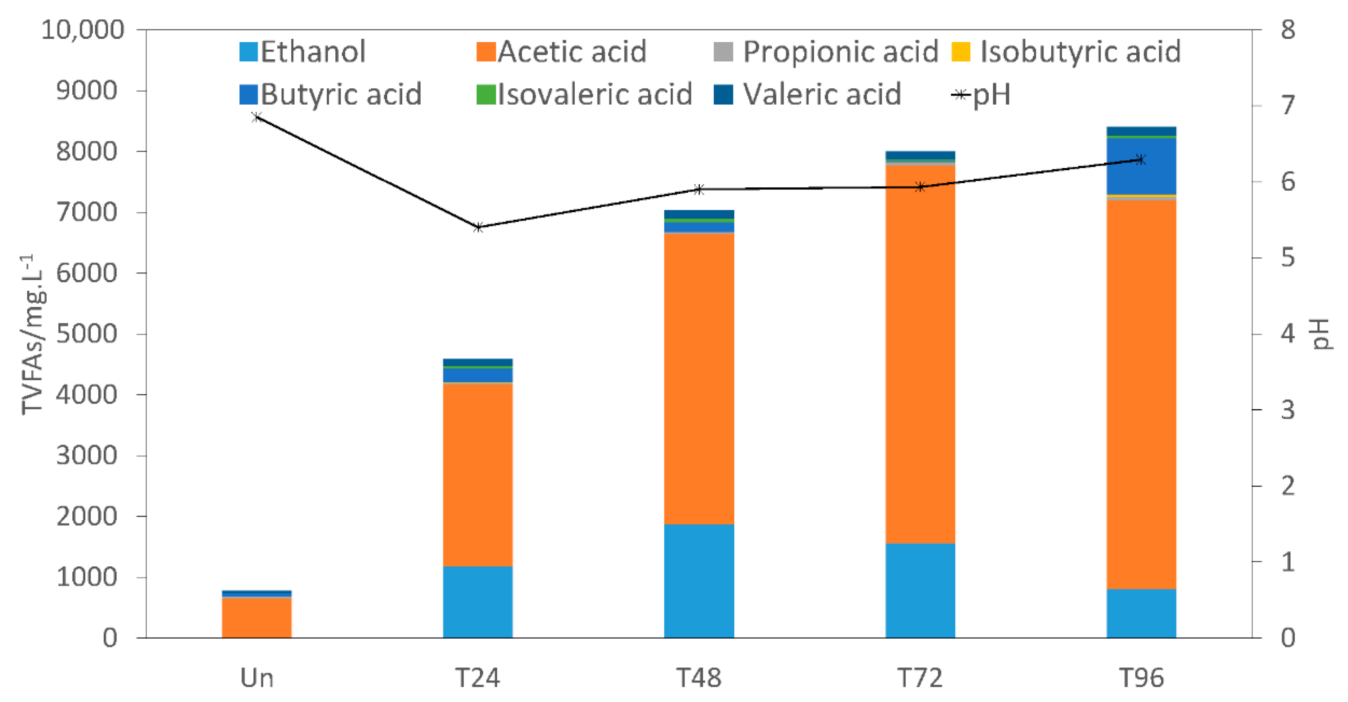

Figure 4. The changes of TVFAs, $\mathrm{pH}$, and ethanol before and after pretreatment. 
To further analyse the influence of pretreatment on CS, the concentrations of TVFAs (including methanol) both before and after pretreatment were measured and shown in Figure 4. At different pretreatment times, the concentration of TVFAs were 4585.8, 7031.6 L, 8001.1 and $8394.1 \mathrm{mg} / \mathrm{L}$, for T24, T48, T72 and T96 groups, which were $488.8 \%, 802.8 \%$, $927.2 \%$ and $977.7 \%$ higher than the untreated group $(778.9 \mathrm{mg} / \mathrm{L})$, respectively. The results manifested that the concentration of TVFAs increased significantly when the pretreatment time was prolonged. In other words, more insoluble substances were hydrolysed with the increase in pretreatment time, which reflected that the complex structure of CS was decomposed, making it more susceptible to hydrolytic enzymes.

For all pretreatment groups, more soluble substances (especially for T96) were released from CS after the pretreatment process, which was beneficial for biomethane production. T24-T72 groups exhibited better AD performance than T96. This could be explained by the fact that CS methanogenesis is promoted at the initial AD stage, but hydrolysis-acidification of the solid part of CS in the whole slurry may be weakened accordingly. In turn, this resulted in a lower biomethane yield and substance bioconversion [36]. This may be one of the reasons why the T96 group had poor AD performance.

In this study, the acetic acid (3002.0-6388.2 mg/L) was the major compound in TVFAsaccounting for $65-78 \%$ of the TVFAs in different pretreatment groups-followed by ethanol (810.4-1865.7 mg/L) — which made up 10-27\% of total TVFA amounts. Similar results have been demonstrated in other studies [31].

In general, the present study results showed that a large proportion of solid materials were transformed into acetic acid and ethanol following pretreatment, which was then used by anaerobic microorganisms to produce biomethane.

\subsubsection{Scanning Electron Microscope (SEM)}

The microstructure deconstruction of CS could improve the accessibility of cellulose for microorganisms, further increasing biomethane production capacity. Therefore, the microstructures of CS before and after pretreatment were observed by SEM.

In Figure 5a, the surface of untreated CS was even and smooth, with fibre bundles arranged orderly; meanwhile, the surface structure was relatively complete without obvious destruction. This dense outer surface formed a protective layer that prevented fungi and bacteria from approaching. Subsequently, this hindered the enzymatic hydrolysis of cellulose and hemicellulose, which was one of the major contributing factors for the low gas production of $\mathrm{AD}$.

For T24 (Figure 5b) and T48 (Figure 5c), some ruptures, cracks and slight delamination appeared on the outer surface, but the fibre bundles remained intact. However, a longer pretreatment time caused more destruction on the CS microstructure. The 72-h pretreatment (T72) altered both internal and external areas of CS (Figure 5d). The CS surface layer was peeled off; moreover, large cracks lead to the exposure of the cellulose skeleton. The porosity and surface area of CS were increased significantly during this process.

The changes mentioned above were beneficial for biomethane production because the increased porosity and exposed cellulose improved the biological accessibility, which made hydrolysation of CS faster and more efficient [7]. The SEM analysis was associated with the optimal result of biomethane yield for the T72 group. Although the 96-h pretreatment group (T96) also led to the most significant changes in the CS microstructure (Figure 5e), the biomethane yield was relatively low, indicating that the microstructural change of CS was not the only factor affecting AD performance. Perhaps the inhibitor produced during the pretreatment process had a greater influence on the biomethane production of CS [31]. Meanwhile, some degraded parts of the outer layer flocked together, recovering the surface and decreasing the total surface area, which could be another reason for the low biomethane yield of the T96 group. 


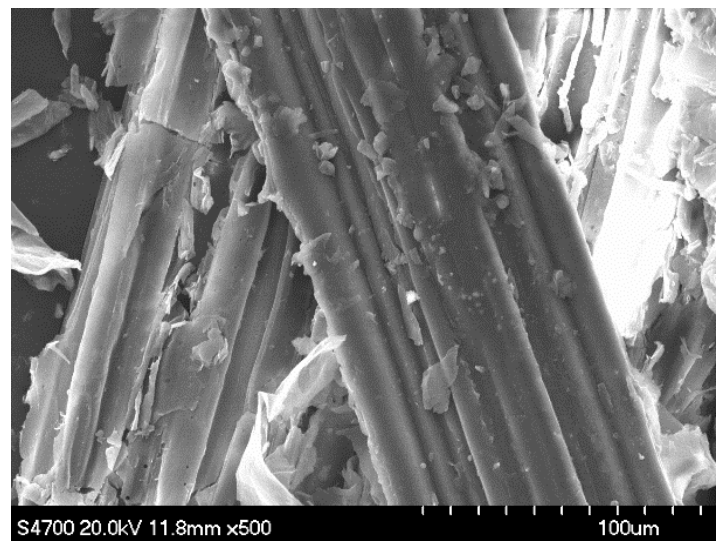

(a)

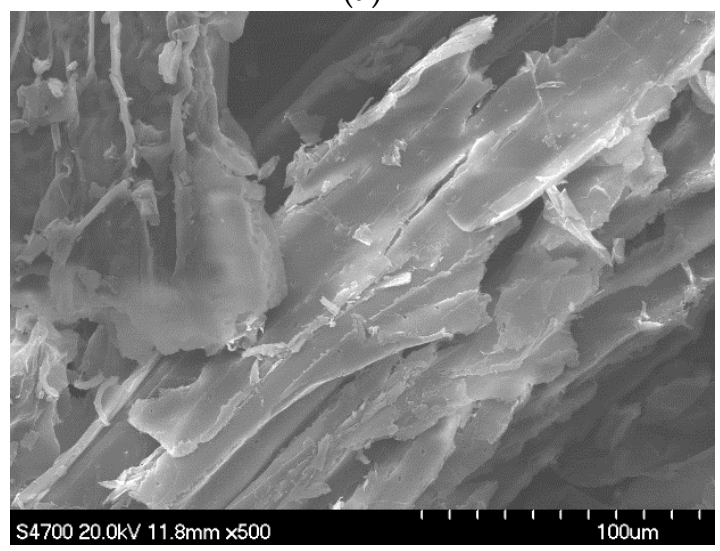

(c)

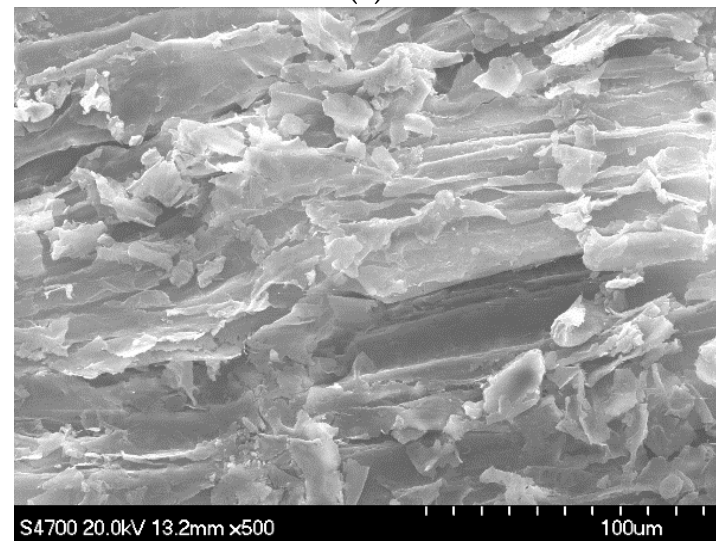

(e)

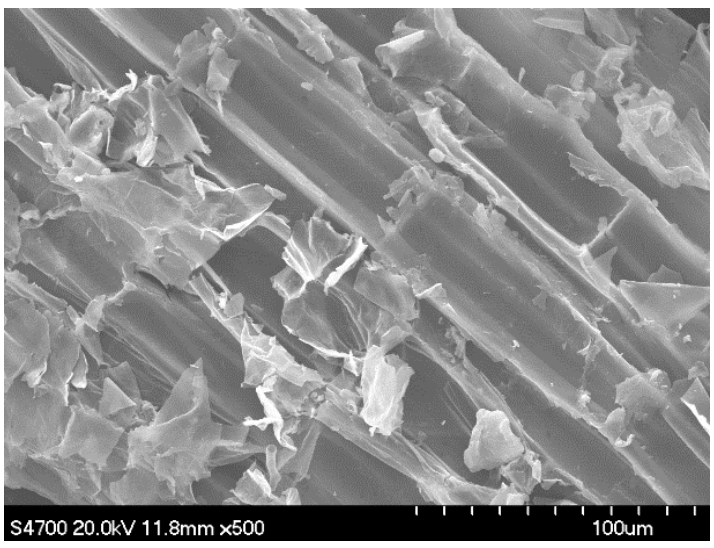

(b)

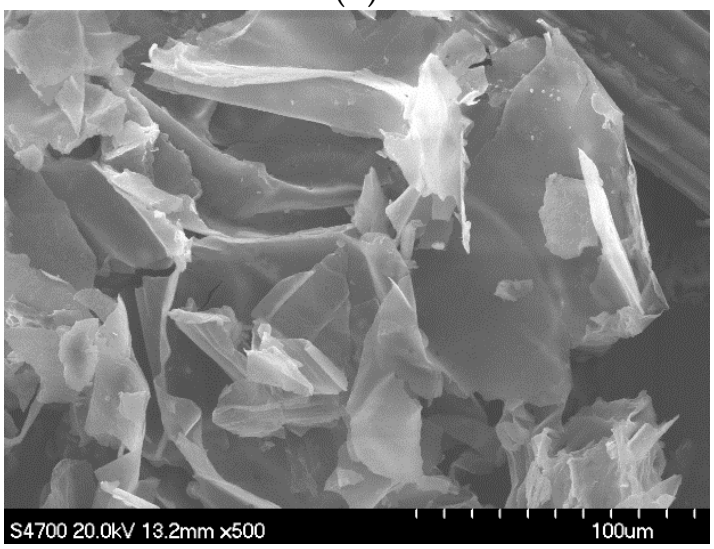

(d)

Figure 5. SEM images of corn stover. (a) Untreated; (b) T24 (Pretreated with 2\% urea for 24 h); (c) T48 (Pretreated with 2\% urea for 48 h); (d) T72 (Pretreated with 2\% urea for 72 h); (e) T96 (Pretreated with 2\% urea for 96 h).

Overall, hydrothermal-urea pretreatment could partly destruct the compact structure of CS, increase the attached area for microbial community growth, and ultimately make it easier to be used in microorganism activity, thus improving the biomethane yield.

\subsubsection{X-ray Diffractometer (XRD)}

Cellulose includes crystalline and non-crystalline structures. The crystallinity of cellulose refers to the fraction of crystalliferous regions of cellulose, which reflects the degree of crystallisation when cellulose aggregates. The XRD spectrum can be used to analyse the degradation of cellulose in CS both before and after pretreatment. Further, XRD data can be used to calculate the crystallinity index of cellulose to better characterise the cellulose crystalline structural changes of CS [32]. 
In this study, there were no significant peak variations at $18^{\circ}, 22^{\circ}$ and $35^{\circ}$ of cellulose I from raw and pretreated CS [37]. However, as is shown in Table 1, the crystallinity index (CrI) of untreated CS was $46.5 \%$, increasing to $48.1 \%, 48.3 \%$ and $48.7 \%$ and decreasing to $44.7 \%$ after $24,48,72$ and $96 \mathrm{~h}$ pretreatment, respectively. It can be inferred that the crystal structure changed after the $50{ }^{\circ} \mathrm{C}$ hydrothermal-urea pretreatment. In addition, different pretreatment times could gently affect the crystallinity of CS, except for the T96 group. With the increase in pretreatment time, the CrI increased from $46.5 \%$ to $48.7 \%$, which indicated that the amorphous region of cellulose was partly destroyed, with the proportion of crystalline region increased accordingly [38]. Alternately, based on previous research, lignin and hemicelluloses were removed by urea pretreatment, which led to an absolute CrI decrease [10]. For the T96 group-in which CrI decreased from $46.5 \%$ to $44.7 \%$ - the possible reason was that the long pretreatment period destroyed the amorphous region and affected the crystalline region of cellulose. Similar trends were reported by Yuan et al. [31] using hydrothermal pretreatment on CS.

Table 1. CrI at different pretreatment times.

\begin{tabular}{ccccc}
\hline Group & Pretreatment Time & $\mathbf{I}_{\mathbf{0 0 2}}{ }^{\mathbf{a}}$ & $\mathbf{I}_{\mathbf{a m}} \mathbf{b}$ & $\mathbf{C r I} \mathbf{( \% )}$ \\
\hline Untreated & $0 \mathrm{~h}$ & $32,933.3$ & $17,608.3$ & 46.5 \\
T24 & $24 \mathrm{~h}$ & 34,575 & 17,950 & 48.1 \\
T48 & $48 \mathrm{~h}$ & $32,783.3$ & $16,958.3$ & 48.3 \\
T72 & $72 \mathrm{~h}$ & 35,650 & 18,275 & 48.7 \\
T96 & $96 \mathrm{~h}$ & 35,075 & $19,408.3$ & 44.7 \\
\hline
\end{tabular}

${ }^{a} I_{002}$ is the diffraction intensity of 002 peak at the diffraction Angle $2 \theta=22.0 ;{ }^{b} I_{a m}$ is the diffraction intensity of peak at the diffraction Angle $2 \theta=18.0$.

Overall, these results revealed that the crystalline allomorph of cellulose from CS was altered to some extent in these pretreatment conditions, which could enhance the biological accessibility of CS.

\subsubsection{Fourier-Transform Infrared Spectroscopy (FTIR)}

The chemical changes of CS during the pretreatment process-such as the solubilisation of lignocellulosic components and breakage of intermolecular bonds-can benefit AD. Hence, the chemical structure changes of pretreated CS were analysed by FTIR analysis, which compared the positions and intensities of different peaks with untreated CS. The spectra of untreated and different pretreated CS are shown in Figure 6, and information of the functional groups for every peak is summarised in Table 2 based on previous research.

Overall, the shape of FTIR before and after pretreatment was similar, but some characteristic intensity peaks of pretreated CS were weakened compared with untreated CS, based on the FTIR data. This indicates that the chemical structure of CS had been changed through the pretreatment. Moreover, the reduced amplitude of adsorption intensities increased with the extension of pretreatment time, implying that the longer the pretreatment time, the more substantial the degradation of the CS chemical structure after pretreatment. 


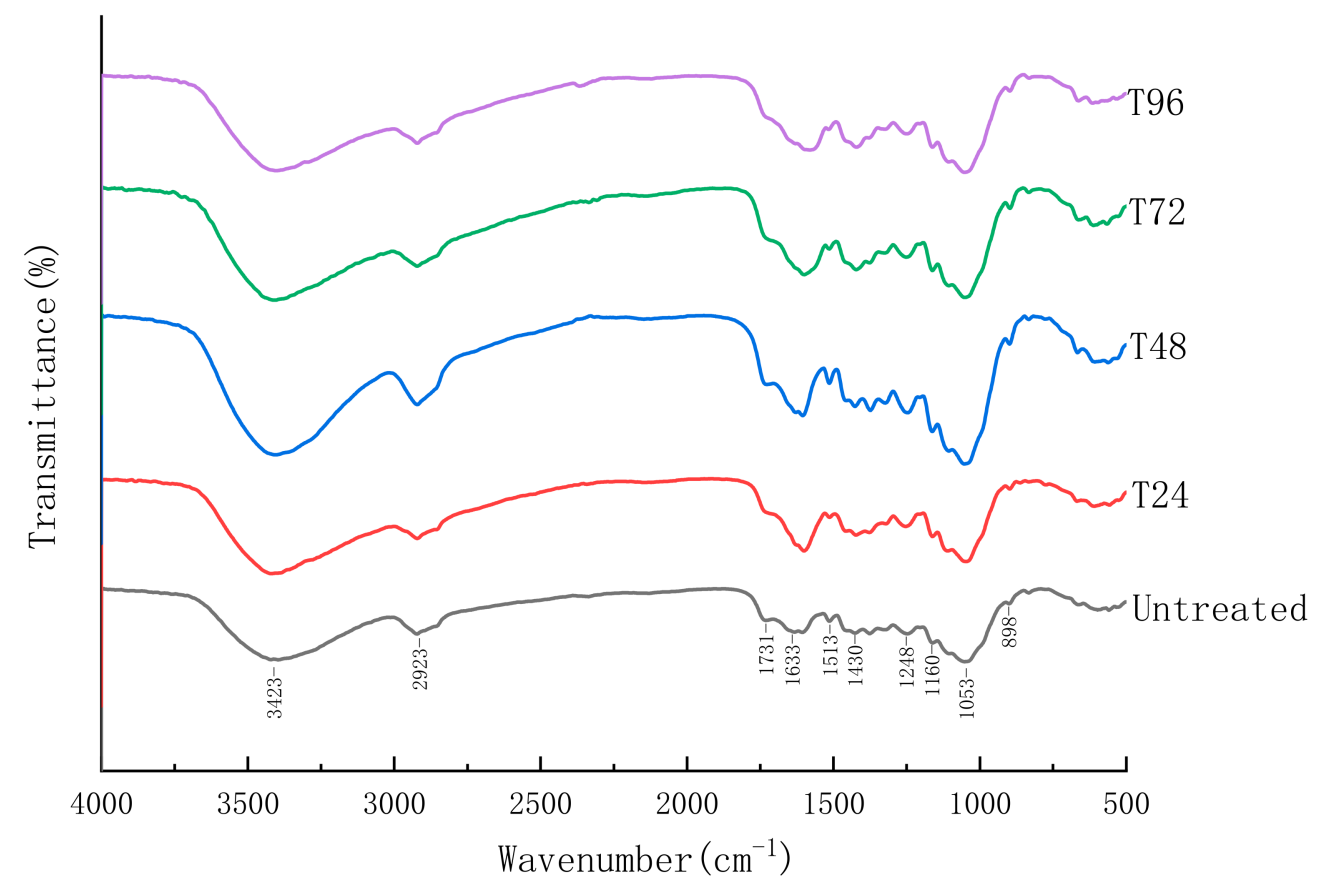

Figure 6. FTIR spectra for pretreated and untreated corn stover.

Table 2. Peak assignment from FTIR spectra.

\begin{tabular}{cc}
\hline Peak Position $\left(\mathbf{c m}^{-\mathbf{1}}\right)$ & Functional Groups \\
\hline 898 & $\beta-(1,4)$-glycosidic bond $(\mathrm{C}-\mathrm{O}-\mathrm{C})$ \\
1052 & $\mathrm{ether}$ bond in hemicellulose $(\mathrm{C}-\mathrm{O}-\mathrm{C})$ \\
1160,1248 & c-O stretching of $\mathrm{COOH}$ and $\mathrm{C}-\mathrm{O}$ vibration of guaiacyl ring \\
1430,1515 & aromatic skeleton vibration \\
1732 & carbonyl group on ester bond between hemicellulose and lignin \\
2919 & $(\mathrm{C}=\mathrm{O})$ \\
3420 & $-\mathrm{CH}_{3},-\mathrm{CH}_{2},-\mathrm{CH}$ in aliphatic compounds \\
\hline
\end{tabular}

The FTIR information can be summarised as the five following observations. (1) The peak observed at $898 \mathrm{~cm}^{-1}$ — which represented a $\beta$-(1,4)-glycosidic bond (C-O-C) [39] decreased, providing the information that the bond between monosaccharide units was broken. Therefore, part of the amorphous cellulose structure was destroyed after pretreatment. This result was consistent with the above CrI value. (2) The stretching vibration appearing at $1053 \mathrm{~cm}^{-1}$ - which represented the ether bond in hemicellulose-declined after pretreatment, reflecting that degradation of semi-cellulose also occurred [25]. (3) The peaks near $1160 \mathrm{~cm}^{-1}$ and $1248 \mathrm{~cm}^{-1}$, represented the C-O stretching of $\mathrm{COOH}$ and C-O vibration of the guaiacyl ring [40] and the peaks at $1430 \mathrm{~cm}^{-1}$ and $1513 \mathrm{~cm}^{-1}$ corresponded to the aromatic skeleton vibration [41]. The intensities of these absorption peaks decreased at different degrees after pretreatment, indicating that the pretreatment could partially break the linkages between the aromatic ring and the aromatic ring skeleton. (4) The peaks located at $1731 \mathrm{~cm}^{-1}$-with stretching vibration stand for $\mathrm{C}=\mathrm{O}$ - weakened and reflected the ester bond between lignin and hemicellulose [42]. The possible reasons for this were determined using the following Equations:

$$
\begin{gathered}
\left(\mathrm{NH}_{2}\right)_{2} \mathrm{CO}+\mathrm{H}_{2} \mathrm{O} \rightleftharpoons \mathrm{CO}_{2}+2 \mathrm{NH}_{3} \\
\mathrm{NH}_{3}+\mathrm{H}_{2} \mathrm{O} \rightleftharpoons \mathrm{NH}_{3} \cdot \mathrm{H}_{2} \mathrm{O}
\end{gathered}
$$




$$
\mathrm{NH}_{3} \cdot \mathrm{H}_{2} \mathrm{O} \rightleftharpoons \mathrm{NH}_{4}{ }^{+}+\mathrm{OH}^{-}
$$

At first, urea could gradually react with water and produce ammonia, which was soluble and formed ammonium hydroxide. After that, the ammonium hydroxide was decomposed to $\mathrm{NH}_{4}{ }^{+}$and $\mathrm{OH}^{-}$. The increase of $\mathrm{OH}^{-}$concentration would catalyse the saponification, which led to the breakage of ester bonds between hemicellulose and lignin. And (5) The peak near $2919 \mathrm{~cm}^{-1}$ was correlated with $-\mathrm{CH}_{3},-\mathrm{CH}_{2}$ and $-\mathrm{CH}$ in aliphatic compounds and the wide-stretching vibration band at $3423 \mathrm{~cm}^{-1}$ was linked to the intermolecular and intramolecular hydrogen bonds present in lignocellulose [43]. After pretreatment, the -OH absorption peak intensity decreased, indicating that the hydrogen bonds between lignocellulose were damaged.

In summary, based on FTIR data, the partial degradation of carbohydrates and ligninwhich contributed to the breakage of chemical and hydrogen bonds in lignocelluloseoccurred to some extent after hydrothermal-urea pretreatment. These internal changes in CS were favoured by $\mathrm{AD}$ microorganisms, having beneficial effects on biomethane production.

\subsection{Microbial Community Analyses}

\subsubsection{Diversity and Richness}

Sobs, Ace and Chao indices were used to characterise the community richness, while the Shannon and Simpson estimator was used to reflect community diversity [44]. Lower values of Sobs, Ace and Chao reflected lower microbial community richness; meanwhile, the higher value of Simpson and lower Shannon indicated a lower microbial diversity. In this study (Table 3), the coverage for all samples were more than 0.99 , which indicated that the sequencing data was reasonable and that the sequencing depth of this experiment could reflect a real-life situation.

Table 3. Microbial community richness and diversity in different pretreatment groups.

\begin{tabular}{cccccccc}
\hline & Group & $\begin{array}{c}\text { Richness } \\
\text { Sobs }\end{array}$ & Ace & Chao & $\begin{array}{c}\text { Diversity } \\
\text { Shannon }\end{array}$ & Simpson & Coverage \\
\hline \multirow{2}{*}{ Bacteria } & T24 & 384 & 476.47 & 511.66 & 3.54 & 0.07 & 0.99 \\
& T48 & 436 & 535.10 & 545.02 & 3.75 & 0.06 & 0.99 \\
& T72 & 467 & 566.79 & 544.68 & 4.05 & 0.043 & 0.99 \\
& T96 & 455 & 538.08 & 532.34 & 3.87 & 0.06 & 0.99 \\
& Untreated & 329 & 417.63 & 404.62 & 2.65 & 0.27 & 0.99 \\
& T24 & 24 & 27.47 & 26 & 1.45 & 0.35 & 0.99 \\
& T48 & 20 & 21.74 & 20 & 1.66 & 0.25 & 0.99 \\
& T72 & 25 & 27.65 & 26.5 & 1.62 & 0.26 & 0.99 \\
& T96 & 21 & 21.75 & 21 & 1.56 & 0.33 & 0.99 \\
& Untreated & 25 & 25.96 & 25.33 & 1.86 & 0.22 & 0.99 \\
\hline
\end{tabular}

For diversity, higher Simpson and lower Shannon indices showed that archaea community had less diversity than the bacteria community, indicating that more kinds of bacteria are involved in anaerobic bioconversion activity than archaea. This agreed with the findings from $\mathrm{Xu}$ et al. [44]. The pretreated CS groups were found to have a higher diversity of bacteria communities than with untreated groups but had no significant difference in archaea community diversity. Considering this higher richness with pretreated CS, it might be assumed that bacterial communities are more susceptible than archaea communities with pretreated CS groups. The difference in richness and diversity might be attributed to the substrate availability between pretreated and untreated CS.

\subsubsection{Bacterial Composition}

For the bacterial compositions at the phylum level (Figure 7a), Firmicutes were the most abundant phylum for all pretreated groups, which accounted for $73.0-74.4 \%$ of total sequences. The dominant bacterium phyla were Bacteroidetes, which accounted for 17.2- 
$22.8 \%$ of all bacteria. There was no significant difference in bacterial compositions for each pretreated sample, meaning that all pretreated samples had similar bacterial communities at the phylum level. The high abundance of Firmicutes suggested that the pretreatment was a suitable method for subsequent biomethane production [45]. However, untreated CS showed an obvious difference in bacterial composition. Bacteroidetes accounted for $58.6 \%$ of total sequences and was the most dominant, followed by Firmicutes (39.9\%), which was relatively lower in the untreated group. The decrease of Firmicutes and increase of Bacteroidetes abundance for the untreated group indicated that the pretreatment could affect the dominant phyla of a bacterial community in the AD process.

Firmicutes is an important hydrolytic-acidifying bacterium. They can degrade lignocellulose into small molecules, providing organic substrates for subsequent methane production [46]. Since CS is a kind of lignocellulosic substrate, hydrolysis is normally a limiting step. Increased Firmicutes abundance should be capable of facilitating cellulose hydrolysis and further acidification processes [45]. At the beginning of AD, more soluble components and easily-degradable substrates caused a rapid profusion of Firmicutes for all pretreated groups due to their high content of easily-degradable components. Hence, a higher abundance of Firmicutes implies a higher ability of hydrolysis and acidification in AD processes of pretreated CS, helping achieve more substance conversion and biomethane yield (See Section 3.1). The dominance and cooperation of Bacteroidetes and Firmicutes promoted the conversion of CS to biomethane while keeping the AD system stable. In terms of facilitating hydrolysis and acidification of cellulose and hemicellulose, higher Firmicute abundance seems more conducive to AD bioconversion than Bacteroidetes.

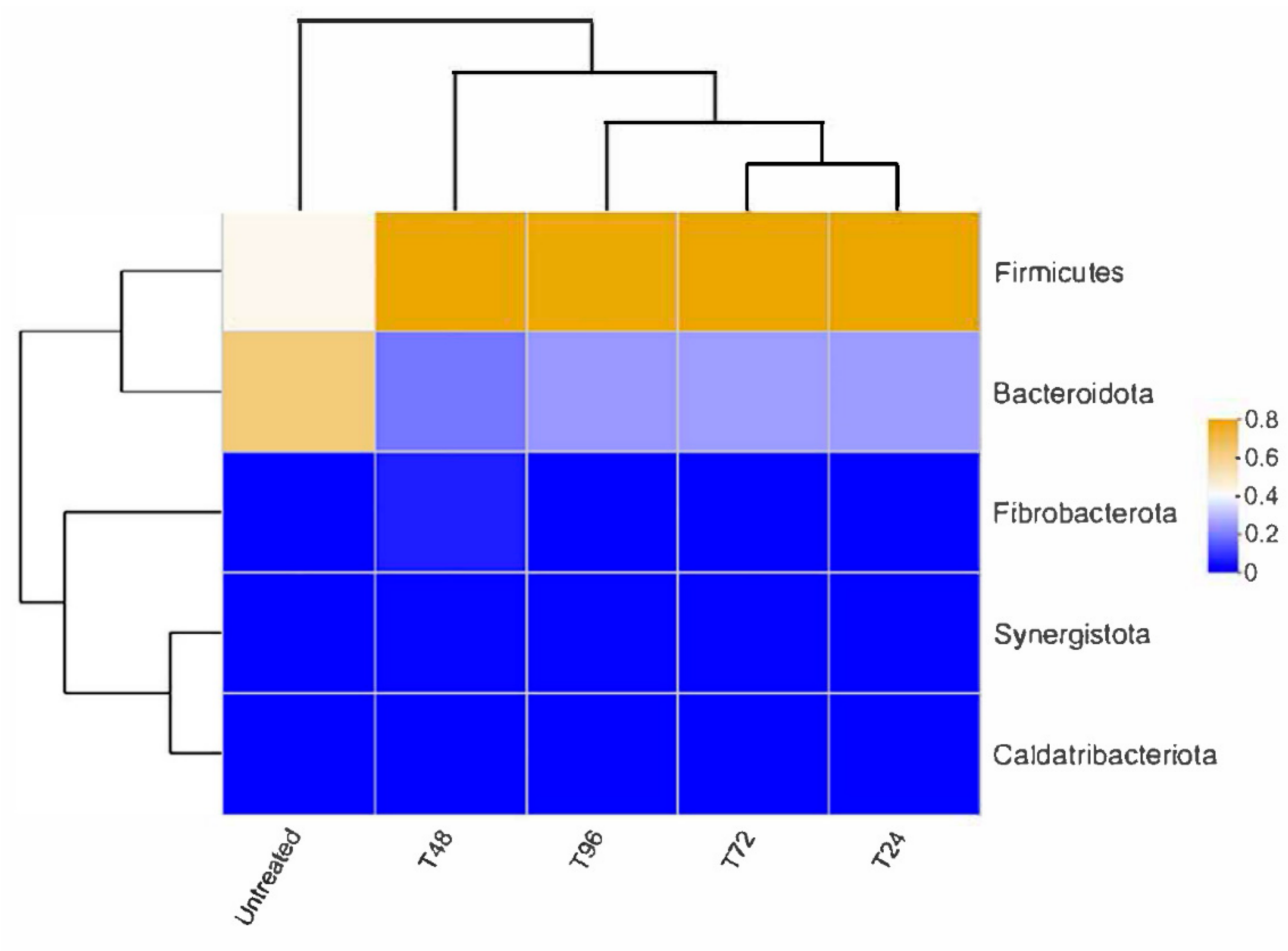

(a)

Figure 7. Cont. 


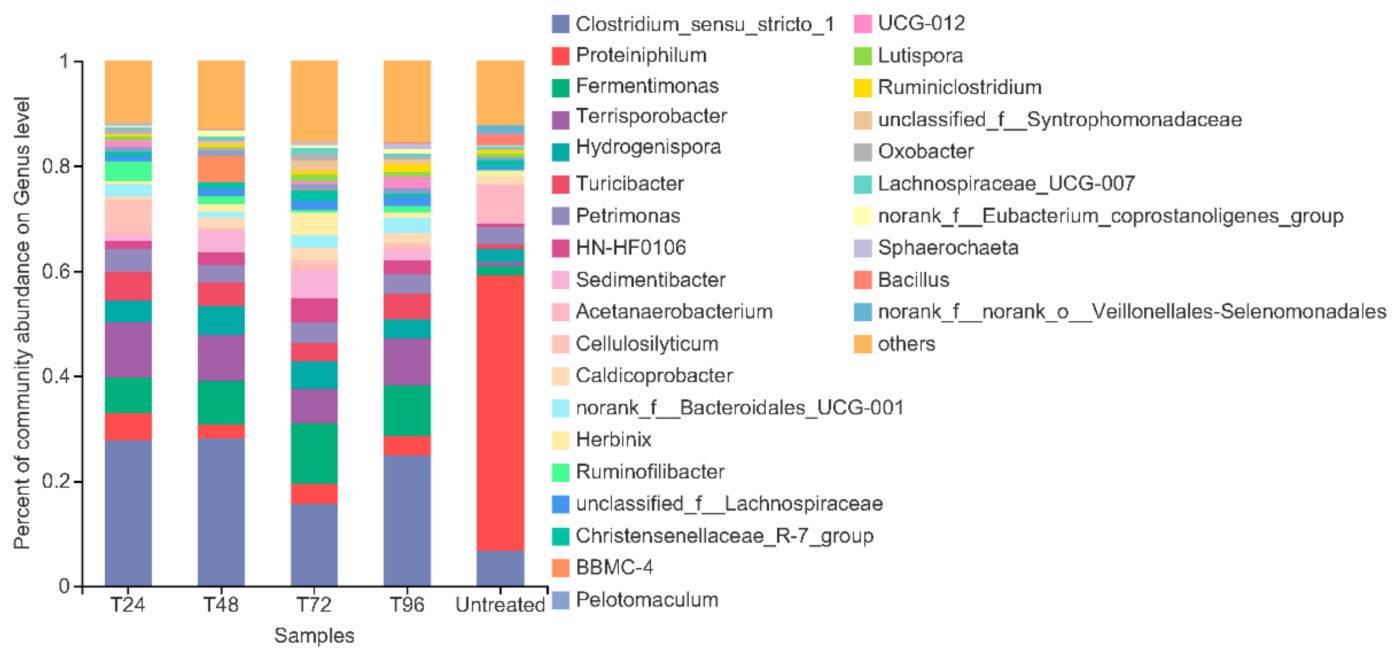

(b)

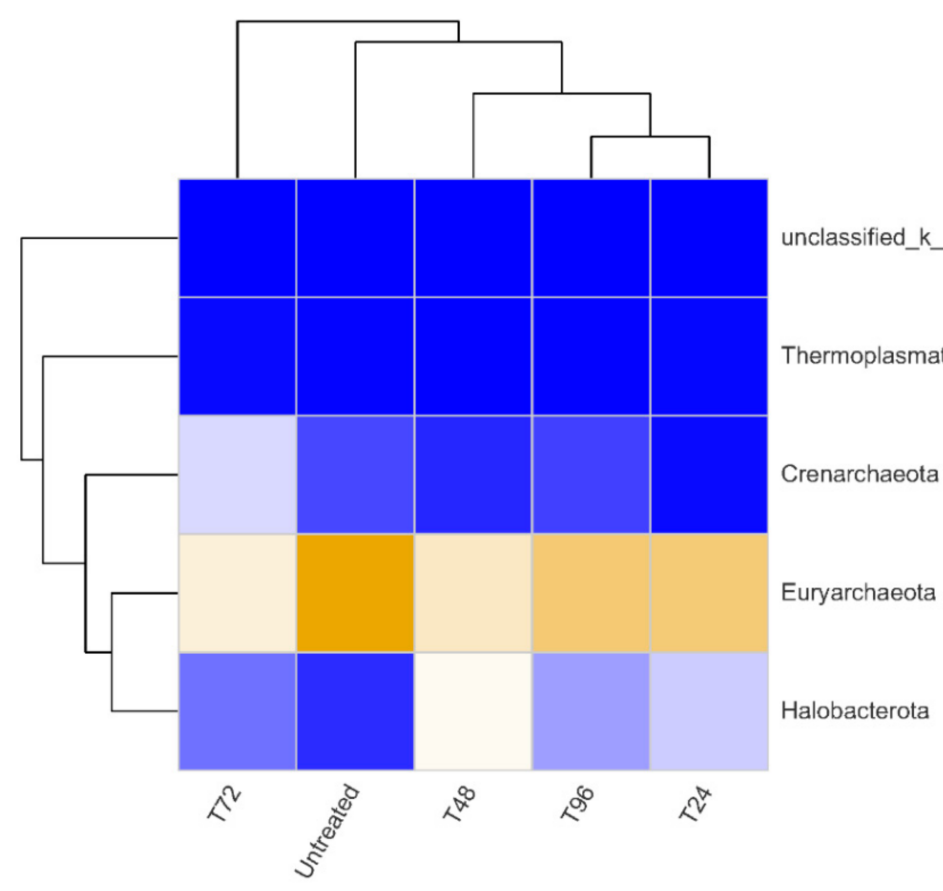

(c)

Figure 7. Cont. 


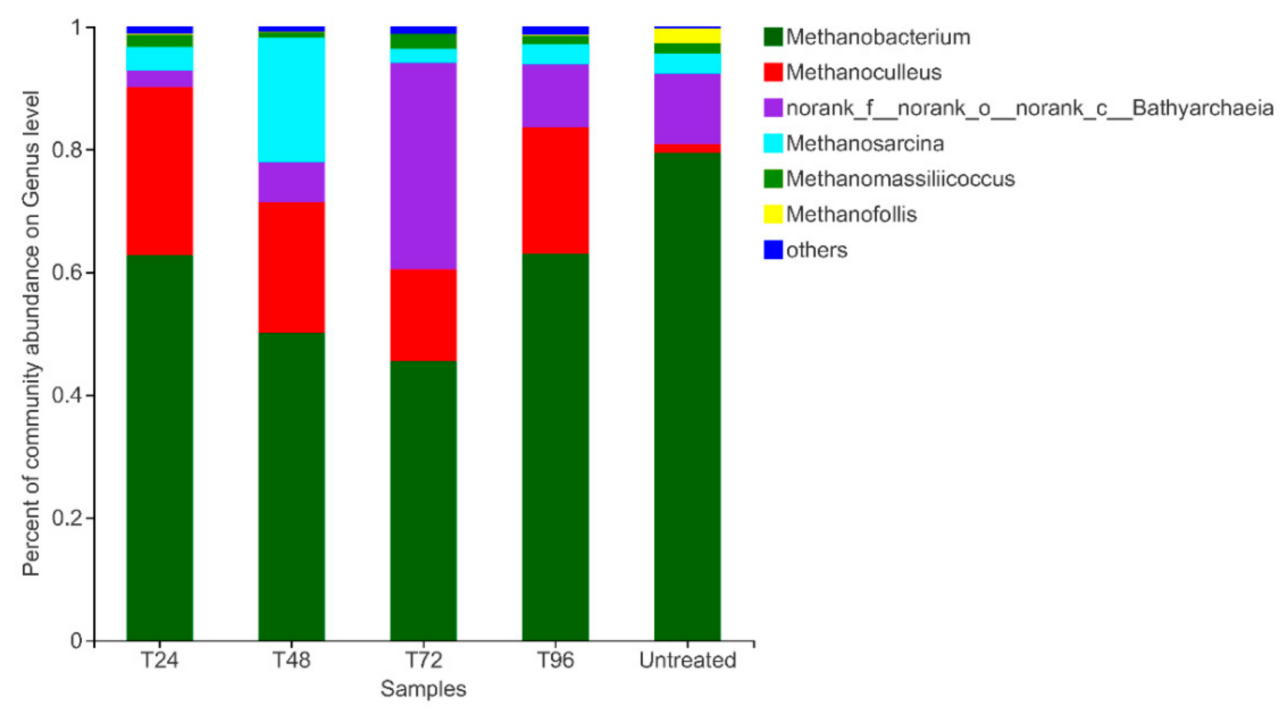

(d)

Figure 7. Community composition analyses: (a) bacterial distributions at Phylum level; (b) bacterial distributions at Genus level; (c) archaeal distributions at Phylum level; (d) archaeal distributions at Genus level.

For the bacterial compositions at the genus level (Figure $7 \mathrm{~b}$ ), twenty-six bacterial sequences were observed for all pretreated CS groups. The top three bacterial genera were Clostridium sensu stricto 1, Fermentimonas and Terrisporobacter according to the abundance ratio. C. sensu stricto 1 was the most dominant genus for all pretreated groups (15.7-28.2\%), followed by Fermentimonas (6.7-11.6\%) and Terrisporobacter (6.7-10.5\%). C. sensu stricto 1 and Terrisporobacter can use organic compounds of CS to produce methanogenesis precursorssuch as acetic acid, butyrate, $\mathrm{H}_{2}$ and $\mathrm{CO}_{2}[47,48]$ - which are important intermediates for methanation. Fermentimonas can convert carbohydrates and cellulose to VFAs, $\mathrm{H}_{2}$ and $\mathrm{CO}_{2}$ Fermentimonas can transfer carbohydrate and cellulose to VFAs, $\mathrm{H}_{2}$, and $\mathrm{CO}_{2}$ [49], which plays an important role in degrading and using carbohydrate-rich substrates. Compared to the untreated group, the enrichment of $C$. sensu stricto 1, Fermentimonas and Terrisporobacter in all pretreated groups indicated that the activity of these genera was enhanced when urea was combined with hydrothermal pretreatment, which was conducive to following AD of CS.

In the present study, the relative abundance of Sedimentibacter in the T72 group was $5.1 \%$, which was considerably higher than those of other pretreated (1.1-3.8\%) and untreated groups $(0.1 \%)$. Moreover, Sedimentibacter was reported to proceed interspecies electron and energy exchange via epilin accessory proteins [50]. Sphaerochaeta species $(1 \%$ in T72 group and $0.06 \%$ in untreated group) could co-culture with methanogens, which may also participate in direct interspecies electron transfer [51]. Syntrophomonadaceae ( $2 \%$ in T72 group and negligible in the untreated group) have also been reported as an electrondonating partner in interspecies electron transfer [52]. The abundance of these species suggests that the pretreatment process could enhance effective interspecies electron transfer in the methanogenesis process.

Proteiniphilum is a protein-hydrolysing bacteria, which mainly uses $\mathrm{N}$-containing substrates to produce several kinds of VFA, $\mathrm{H}_{2}$ and $\mathrm{CO}_{2}$ [53,54]. For untreated CS, 10 bacterial sequences were observed, with Proteiniphilum being the most dominant, accounting for $52.4 \%$ abundance. However, the relative abundance of this genus decreased significantly in all pretreated groups. This was probably in response to pretreatment removing the crude protein in CS [55], resulting in a nutrient deficiency of this microorganism and restricting its growth and reproduction. Although Proteiniphilum was beneficial to the bioconversion of CS, other important bacteria such as C. sensu stricto 1, Fermentimonas and Terrisporobacter 
were lacking, limiting the role of Proteiniphilum in achieving overall high efficiency for untreated CS.

\subsubsection{Archaeal composition}

Figure $7 \mathrm{c}$ shows the archaeal community at phylum level. Three archaeal communities were dominant in all groups, namely Euryarchaeota, Halobacterota and Crenarchaeota. Euryarchaeota was the most dominant species, which had a relative abundance of $46.4-64.0 \%$ and $79.3 \%$ in pretreated and untreated groups, respectively. Euryarchaeota is important for $\mathrm{AD}$ of $\mathrm{CS}$, as it could play a vital role in converting lignocellulose to biomethane (Xu et al. [44] and Guan et al. [56]). Halobacterota populations are considered cellulo-/chininotrophic archaea, which participate in metabolising recalcitrant organic polymers [57]. Halobacterota seemed to be enriched for all pretreated groups, indicating that the microbes in the pretreated groups could had a stronger ability to utilise complex polysaccharides in CS. Crenarchaeota can grow by using reductive inorganic compoundssuch as $\mathrm{H}_{2}$ and elemental sulfur-and play an essential role in using $\mathrm{C} 1$ compounds (such as $\mathrm{CO}_{2}$ ) [58]. A higher abundance of Crenarchaeota as observed in the T72 group was assumed to reinforce the pathway of $\mathrm{H}_{2} / \mathrm{CO}_{2}$ to $\mathrm{CH}_{4}$, leading to increased biomethane production in the T72 group.

Figure $7 \mathrm{~d}$ presented the archaeal abundance at the genus level. Six archaeal sequenceswere observed, with the most dominant archaeal genus being Methanobacterium for all sa-mples (45.6-79.1\%), followed by Methanoculleus (14.9-27.1\%) and Norank_f_norank_o_norank_c_Bathyarchaeia (2.7-33.7\%).

Methanobacterium is a hydrogenotrophic methanogen, converting $\mathrm{H}_{2}$ and $\mathrm{CO}_{2}$ to methane [59]. The relatively high proportion of this genus implies that $\mathrm{CH}_{4}$ synthesis from $\mathrm{H}_{2}$ and $\mathrm{CO}_{2}$ might be an important pathway for all groups. The other hydrogenotrophic genus, Methanoculleus, is able to cooperate with syntrophic bacteria to produce biomethane from cellulose-rich substrates during $\mathrm{AD}$ [60]. It was also reportedly responsible for enhanced biomethane yields in manure-bases AD [60]. A decline of Methanoculleus from $15 \%$ to $27.3 \%$ in pretreated groups to $1.5 \%$ in the untreated group was observed. These results indicate that the pretreatment process influenced the activity of this genus, and the lack of this genus may lead to low biomethane yields. Compared with other groups, N.f.n.o.n.c. Bathyarchaeia was found predominantly in the T72 group, which demonstrated the best AD performance. It seems that N.f.n.o.n.c. Bathyarchaeia might have the ability to enhance the synergistic effect of microorganisms during hydrolysis-acidification and methanogenesis. N.f.n.o.n.c. Bathyarchaeia is thought to be cellulolytic archaea, which contributes to cellulose conversion in recalcitrant lignocellulosic material, as Li et al. [61] reported. At the hydrolysis-acidification phase, its enrichment would be conducive to the efficient cellulose degradation of CS, hence providing more readily available substances for the methanogenesis phase in the T72 group.

For the untreated group, it had the highest abundance of Methanobacterium (79.4\%). The variation of this genus between untreated and pretreated groups $(45.5-63.1 \%)$ was likely due to the pretreatment effect. Compared with the pretreated groups, the untreated group took longer for hydrolysis-acidification - and the $\mathrm{H}_{2}$ production via hydrolysisacidification was consequently delayed - which led to the high abundance of hydrogentrophic Methanobacterium in the end of AD. This could be further explained by DMP figures (See Section 3.1.1). The pretreatment groups completed the hydrolysis-acidification process in the earlier period, while the untreated group kept producing $\mathrm{H}_{2}$ for a longer time. This further induced reproduction and resulted in a high abundance of hydrogenotrophic Methanobacterium at the later stage. This finding was also similar to the report by $\mathrm{Xu}$ et al. [45].

\subsubsection{Correlation between Microbial Community and Environmental Characteristics}

Redundancy analysis (RDA) was applied further to understand the relationship between microbial community and environmental factors. The top five bacterial species and archaeal species based on relative abundance at genus level were selected for Figure 8. 
After removing redundant variables, the concentration of butyric acid, ethanol and acetic acid after pretreatment (pretreatment effect) and methane yield (AD performance) were chosen as environmental factors for RDA.

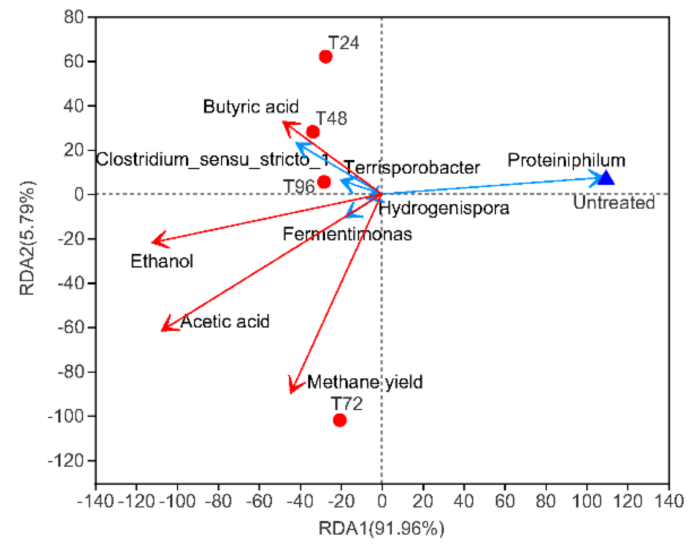

(a)

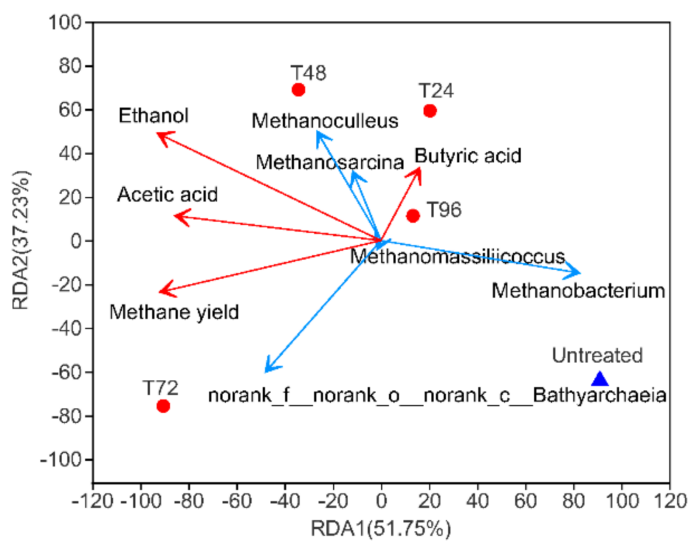

(b)

Figure 8. Redundancy analysis (RDA) analysis of: (a) bacterial communities at Genus level; (b) archaeal communities at Genus level. Red arrows represent environmental factors; blue arrows represent species; scattered dots represent experiment groups.

The RDA analysis (Figure 8a,b) showed that urea combined with a mild temperature hydrotherm pretreatment could affect the microbial community structure, which could lead to the domestication and propagation of specific bacteria and archaea in the AD system. In total, $97.75 \%$ and $88.98 \%$ variation in bacterial/archaeal community composition were explained by RDA1 and RDA2 in the digesters, respectively. The microbials of bacteria and archaea in T24, T48 and T96 groups were closed, while the microbiota in T72 showed a major shift on the RDA plot from other groups, indicating potential divergence in the microbial composition in response to the pretreatment process; which leads to further biomethane yield. However, the digester with untreated CS showed microbiota clusters that were relatively far off from each other, reflecting a poor AD performance.

Acetic acid had the highest positive correlation with methane yield, which was considered an important precursor for methanogenesis. According to this study, nearly $70 \%$ of biomethane is converted from acetic acid in the AD process because it is one of the organic substrates directly used in methanogenesis [57]. Therefore, the increased concentration of acetic acid in pretreated CS was conducive to biomethane production for subsequent AD.

For the bacteria at the genus level (Figure 8a), C. sensu stricto 1 and Terrisporobacter had positive correlations with butyric acid. These results imply that these bacteria were mainly involved in butyric acid fermentation after pretreatment, which was similar to previous study [48]. Proteiniphilum showed significant negative effects on ethanol, acetic acid and butyric acid, which revealed that TVFAs may inhibit the genus during the AD system. Fermentimonas positively correlated with acetic acid, ethanol and methane yield. The domestication of Fermentimonas was related to the metabolism of various TVFAs, and the succession of Fermentimonas could be beneficial to improving biomethane production during the $\mathrm{AD}$ process [49].

For the archaea at the genus level (Figure 8b), Methanobacterium was negatively correlated with ethanol, acetic acid and biomethane yield. This result confirmed that Methanobacterium was hydrotrophic towards methanogens, which relied on $\mathrm{H}_{2}$ and $\mathrm{CO}_{2}$ as substrates for methanogenesis rather than acetate [56]. According to present research, nearly $70 \%$ of biomethane is produced via acetic acid-methane pathways [56]. The high relative abundance of Methanobacterium in the untreated group may reflect the deficiency of hydrolysis-acidification processes, which may lead to a lack of acetic acid for subsequent methanogenesis. Therefore, Methanobacterium had a negative relation with biomethane 
yield. A similar result was found by Li et al., indicating their limited role in methanogenesis [60].

The genus Methanosarcina is both acetoclastic and hydrogenotrophic in its methanogenesis, which could use either acetic acid or $\mathrm{H}_{2} / \mathrm{CO}_{2}$ as methanogenic substrates [62]. However, Methanoculleus and Methanosarcina showed low positive correlations with butyric acid, ethanol and acetic acid, and had no obvious correlations with methane yield. Perhaps these microbials played a more substantial role in biomethane production at an earlier stage in the AD process.

The negative correlation between N.f.n.o.n.c. Bathyarchaeia and butyric acid suggests that butyric acid probably inhibits the growth of this microorganism. In this study, the main species driving methane yield was N.f.n.o.n.c. Bathyarchaeia, which had the highest positive effect of methane yields. This genus coordinated with other methanogens via symbiotic associations and promoted biomethane production [63]. N.f.n.o.n.c. Bathyarchaeia was enriched in the T72 group (33.7\%), responsible for enhanced biomethane production performance.

\section{Conclusions}

This study proposed a novel method that integrates two methods as a combined approach for CS pretreatment. The method used urea combined with a mild temperature hydrotherm to pretreat CS, and assessed its resulting effect on AD performance, microstructure and corresponding microbial community growth. This combined treatment was proven to be effective in improving AD performance of CS. With just $2 \%$ urea set at 50 ${ }^{\circ} \mathrm{C}$, a 72-h hydrotherm pretreatment resulted in a maximum biomethane yield of $205 \mathrm{~mL} / \mathrm{g}$ $\mathrm{VS}^{-1}$, with vs. and TS removal rates of $69.3 \%$ and $47.7 \%$. These rates were $36.7 \%, 25.3 \%$ and $27.5 \%$ higher than rates observed in untreated samples $(p<0.05)$. More soluble substances were released to the liquid phase after pretreatment was conducted, which was considered one reason for higher biomethane production. SEM, XRD and FTIR analyses reflected that this pretreatment could alter CS physicochemical structures to some extent. The most considerable differences were observed in microbial richness, diversity and bacterial and archaeal community compositions between pretreated and untreated groups, which were considered as important factors contributing to improved AD performance. This study indicated that the proposed combined pretreatment approach could be one of the most effective methods for biomethane production from CS. However, the specific hydrolysed products generated after pretreatment and their resulting effect on microbial activity is still unclear. Future studies on the isolation and identification of hydrolysate are required to further elucidate this pretreatment's internal mechanism.

Supplementary Materials: The following are available online at https:/ /www.mdpi.com/article/10 $.3390 /$ polym13132207/s1, Characteristics of feedstock and inoculum used and the primer design for subsequent bacterial and archaeal DNA extraction were listed in Supporting Information (Tables S1, S2, supplied as the Supporting Information).

Author Contributions: Conceptualization, X.L. and Y.L.; Methodology, X.L. and Y.L.; Validation, X.L., H.Y. and X.Z.; Formal Analysis, Y.L.; Investigation, Y.L.; Resources, H.Y.; X.Z. and Y.C.; Data Curation, Y.L. and Y.C.; Writing-Original Draft Preparation, Y.L.; Writing-Review \& Editing, X.L.; Visualization, Y.L. and Y.C.; Supervision, X.L.; H.Y. and X.Z.; Project Administration, X.L.; Funding Acquisition, X.L. All authors have read and agreed to the published version of the manuscript.

Funding: This research has been funded by the Chinese governments through the Operational Program "Novel Technology of Biomass Gas Production through Combining Anerobic Digestion with Gasification" by the "Thirteenth-five" Key R\&D Plan-international cooperation" project (2018YFE0111000).

Acknowledgments: The authors are grateful to the fund supports from Novel Technology of Biomass Gas Production through Combining Anerobic Digestion with Gasification. The State "Thirteenth-five" Key R\&D Plan-international cooperation project among governments (2018YFE0111000).

Conflicts of Interest: The authors declare no conflict of interest. 


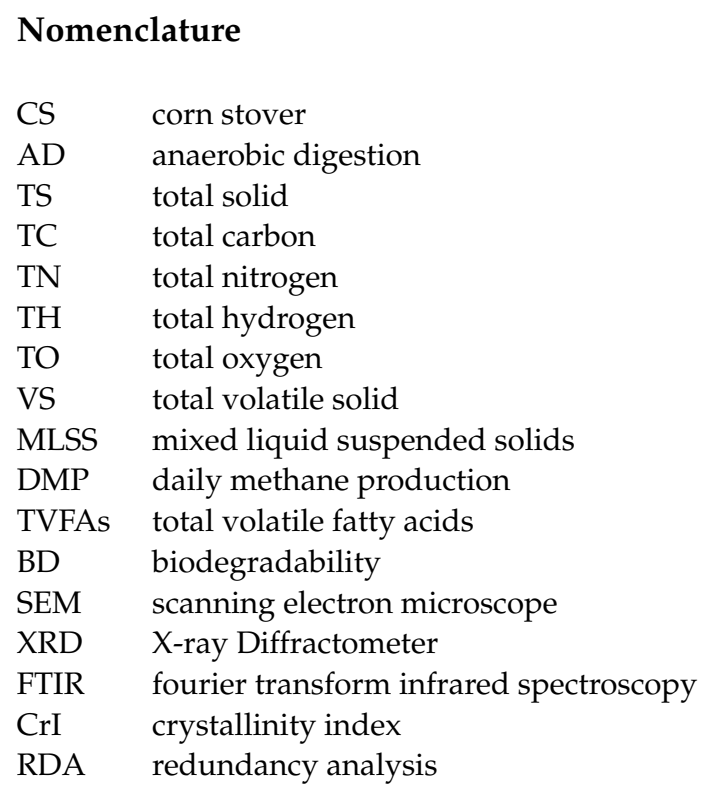

\section{References}

1. The National Bureau of Statistics. China Statistical Yearbook. Available online: http://www.stats.gov.cn/tjsj/ndsj/2020/indexch. htm (accessed on 28 October 2020).

2. Zhao, S.G.; Li, G.D.; Zheng, N.; Wang, J.Q.; Yu, Z.T. Steam explosion enhances digestibility and fermentation of corn stover by facilitating ruminal microbial colonization. Bioresour. Technol. 2018, 253, 244-251. [CrossRef] [PubMed]

3. Aho, M.; Paakkinen, K.; Taipale, R. Quality of deposits during grate combustion of corn stover and wood chip blends. Fuel 2013, 104, 476-487. [CrossRef]

4. Huang, H.; Wang, Z.; Pan, S.C.; Shoup, L.M.; Felix, T.L.; Perkins, J.B.; May, O.; Singh, V. Fungal pretreatment to improve digestibility of corn stover for animal feed. Trans. Asabe 2017, 60, 973-979. [CrossRef]

5. Powers, S. Quantifying Cradle-to-Farm Gate Life-Cycle Impacts Associated with Fertilizer Used for Corn, Soybean, and Stover Production. Battelle Natl. Renew. Energy Lab. 2005. [CrossRef]

6. Sharma, H.K.; Xu, C.B.; Qin, W.S. Biological Pretreatment of Lignocellulosic Biomass for Biofuels and Bioproducts: An Overview. Waste Biomass Valorization 2019, 10, 235-251. [CrossRef]

7. Kumari, D.; Singh, R. Pretreatment of lignocellulosic wastes for biofuel production: A critical review. Renew. Sustain. Energy Rev. 2018, 90, 877-891. [CrossRef]

8. Stamatelatou, K.; Antonopoulou, G.; Ntaikou, I.; Lyberatos, G. The Effect of Physical, Chemical, and Biological Pretreatments of Biomass on its Anaerobic Digestibility and Biogas Production. In Biogas Production; Scrivener Publishing LLC: Salem, MA, USA, 2012; pp. 55-90. [CrossRef]

9. Zheng, M.; Li, L.; Li, X.; Xiong, J.; Mei, T.; Chen, G. The Effects of Alkaline Pretreatment Parameters on Anaerobic Biogasification of Corn Stover. Energy Sources Part A Recovery Util. Environ. Eff. 2010, 32, 1918-1925. [CrossRef]

10. He, Y.F.; Pang, Y.Z.; Liu, Y.P.; Li, X.J.; Wang, K.S. Physicochemical characterization of rice straw pretreated with sodium hydroxide in the solid state for enhancing biogas production. Energy Fuels 2008, 22, 2775-2781. [CrossRef]

11. Jaffar, M.; Pang, Y.Z.; Yuan, H.R.; Zou, D.X.; Liu, Y.P.; Zhu, B.N.; Korai, R.M.; Li, X.J. Wheat straw pretreatment with KOH for enhancing biomethane production and fertilizer value in anaerobic digestion. Chin. J. Chem. Eng. 2016, 24, 404-409. [CrossRef]

12. Yuan, H.R.; Li, R.P.; Zhang, Y.T.; Li, X.J.; Liu, C.M.; Meng, Y.; Lin, M.N.; Yang, Z.Y. Anaerobic digestion of ammonia-pretreated corn stover. Biosyst. Eng. 2015, 129, 142-148. [CrossRef]

13. Li, Q.; Yang, F.L.; Zheng, G.X.; Guan, Z.J. Effects of urea ammonia pretreatment on the batch anaerobic fermentation efficiency of corn stovers. Int. J. Agric. Biol. Eng. 2019, 12, 169-173. [CrossRef]

14. Mohsenzadeh, A.; Jeihanipour, A.; Karimi, K.; Taherzadeh, M.J. Alkali pretreatment of softwood spruce and hardwood birch by $\mathrm{NaOH}$ /thiourea, $\mathrm{NaOH}$ / urea, $\mathrm{NaOH}$ / urea/thiourea, and $\mathrm{NaOH} / \mathrm{PEG}$ to improve ethanol and biogas production. J. Chem. Technol. Biotechnol. 2012, 87, 1209-1214. [CrossRef]

15. Yao, Y.Q.; Bergeron, A.D.; Davaritouchaee, M. Methane recovery from anaerobic digestion of urea-pretreated wheat straw. Renew. Energy 2017, 115, 139-148. [CrossRef]

16. Yu, Q.; Cui, S.F.; Sun, C.; Liu, R.H.; Sarker, M.; Guo, Z.J.; Lai, R.Y. Synergistic Effects of Anaerobic Co-Digestion of Pretreated Corn Stover with Chicken Manure and Its Kinetics. Appl. Biochem. Biotechnol. 2021, 193, 515-532. [CrossRef]

17. Li, J.; Wachemo, A.C.; Yuan, H.R.; Zuo, X.Y.; Li, X.J. Evaluation of system stability and anaerobic conversion performance for corn stover using combined pretreatment. Waste Manag. 2019, 97, 52-62. [CrossRef] [PubMed]

18. Wang, W.; Tan, X.S.; Guo, Y.; Zhang, B.W.; Chen, X.Y.; Yu, Q.; Zhuang, X.S.; Yuan, Z.H. Mild Urea/KOH pretreatment to enhance enzymatic hydrolysis of corn stover with liquid waste recovery for plant growth. J. Clean. Prod. 2021, 284, 9. [CrossRef] 
19. Yu, Q.; Sun, C.; Liu, R.H.; Yellezuome, D.; Zhu, X.P.; Bai, R.F.; Liu, M.Q.; Sun, M.Z. Anaerobic co-digestion of corn stover and chicken manure using continuous stirred tank reactor: The effect of biochar addition and urea pretreatment. Bioresour. Technol. 2021, 319, 8. [CrossRef]

20. Sato, A.; Soeprijanto, S.; Widjaja, A. Influence of Alkaline Hydrothermal Pretreatment of Rice Straw on Biomass Composition. Int Energy J. 2019, 19, 115-124.

21. Song, Z.; Sun, X.; Yang, G.; Yan, Z.; Yuan, Y.; Li, D.; Li, X.; Liu, X. Effect of NaOH pretreatment on methane yield of corn straw at different temperatures by anaerobic digestion. Huagong Xuebao/CIESC J. 2014, 65, 1876-1882. [CrossRef]

22. Pang, Y.Z.; Liu, Y.P.; Li, X.J.; Wang, K.S.; Yuan, H.R. Improving biodegradability and biogas production of corn stover through sodium hydroxide solid state pretreatment. Energy Fuels 2008, 22, 2761-2766. [CrossRef]

23. Li, X.; Li, L.Q.; Zheng, M.X.; Fu, G.Z.; Lar, J.S. Anaerobic Co-Digestion of Cattle Manure with Corn Stover Pretreated by Sodium Hydroxide for Efficient Biogas Production. Energy Fuels 2009, 23, 4635-4639. [CrossRef]

24. Siddique, M.N.I.; Wahid, Z.A. Achievements and perspectives of anaerobic co-digestion: A review. J. Clean. Prod. 2018, 194, 359-371. [CrossRef]

25. Li, J.; Wachemo, A.C.; Yu, G.Q.; Li, X.J. Enhanced anaerobic digestion performance of corn stalk pretreated with freezing-thawing and ammonia: An experimental and theoretical study. J. Clean. Prod. 2020, 247, 12. [CrossRef]

26. APHA. Standard Methods for the Examination of Water and Wastewater, 21st ed.; American Public Health Association (APHA): Washington, DC, USA, 2005.

27. Mustafa, A.M.; Li, H.; Radwan, A.A.; Sheng, K.C.; Chen, X. Effect of hydrothermal and $\mathrm{Ca}(\mathrm{OH})(2)$ pretreatments on anaerobic digestion of sugarcane bagasse for biogas production. Bioresour. Technol. 2018, 259, 54-60. [CrossRef]

28. Yao, Y.Q.; He, M.L.; Ren, Y.B.; Ma, L.Y.; Luo, Y.; Sheng, H.M.; Xiang, Y.; Zhang, H.; Li, Q.; An, L.Z. Anaerobic digestion of poplar processing residues for methane production after alkaline treatment. Bioresour. Technol. 2013, 134, 347-352. [CrossRef] [PubMed]

29. Li, Y.Q.; Zhang, R.H.; He, Y.F.; Liu, X.Y.; Chen, C.; Liu, G.Q. Thermophilic Solid-State Anaerobic Digestion of Alkaline-Pretreated Corn Stover. Energy Fuels 2014, 28, 3759-3765. [CrossRef]

30. Zhang, H.Y.; Wang, L.G.; Dai, Z.Q.; Zhang, R.H.; Chen, C.; Liu, G.Q. Effect of organic loading, feed-to-inoculum ratio, and pretreatment on the anaerobic digestion of tobacco stalks. Bioresour. Technol. 2020, 298, 8. [CrossRef]

31. Yuan, H.R.; Song, X.C.; Guan, R.L.; Zhang, L.; Li, X.J.; Zuo, X.Y. Effect of low severity hydrothermal pretreatment on anaerobic digestion performance of corn stover. Bioresour. Technol. 2019, 294, 7. [CrossRef]

32. Bolado-Rodriguez, S.; Toquero, C.; Martin-Juarez, J.; Travaini, R.; Garcia-Encina, P.A. Effect of thermal, acid, alkaline and alkaline-peroxide pretreatments on the biochemical methane potential and kinetics of the anaerobic digestion of wheat straw and sugarcane bagasse. Bioresour. Technol. 2016, 201, 182-190. [CrossRef]

33. Hattori, S. Syntrophic acetate-oxidizing microbes in methanogenic environments. Microbes Environ. 2008, 23, 118-127. [CrossRef]

34. Song, X.C.; Wachemo, A.C.; Zhang, L.; Bai, T.Q.; Li, X.J.; Zuo, X.Y.; Yuan, H.R. Effect of hydrothermal pretreatment severity on the pretreatment characteristics and anaerobic digestion performance of corn stover. Bioresour. Technol. 2019, 289, 8. [CrossRef] [PubMed]

35. Laser, M.; Schulman, D.; Allen, S.G.; Lichwa, J.; Antal, M.J.; Lynd, L.R. A comparison of liquid hot water and steam pretreatments of sugar cane bagasse for bioconversion to ethanol. Bioresour. Technol. 2002, 81, 33-44. [CrossRef]

36. Xiang, C.X.; Tian, D.; Hu, J.G.; Huang, M.; Shen, F.; Zhang, Y.Z.; Yang, G.; Zeng, Y.M.; Deng, S.H. Why can hydrothermally pretreating lignocellulose in low severities improve anaerobic digestion performances? Sci. Total Environ. 2021, 752, 10. [CrossRef]

37. Zhang, H.; Ning, Z.F.; Khalid, H.; Zhang, R.H.; Liu, G.Q.; Chen, C. Enhancement of methane production from Cotton Stalk using different pretreatment techniques. Sci. Rep. 2018, 8, 9. [CrossRef]

38. Wang, Z.W.; Zhu, M.Q.; Li, M.F.; Wei, Q.; Sun, R.C. Effects of hydrothermal treatment on enhancing enzymatic hydrolysis of rapeseed straw. Renew. Energy 2019, 134, 446-452. [CrossRef]

39. Liu, L.; Sun, J.S.; Li, M.; Wang, S.H.; Pei, H.S.; Zhang, J.S. Enhanced enzymatic hydrolysis and structural features of corn stover by $\mathrm{FeCl}_{3}$ pretreatment. Bioresour. Technol. 2009, 100, 5853-5858. [CrossRef]

40. Wahab, M.A.; Jellali, S.; Jedidi, N. Ammonium biosorption onto sawdust: FTIR analysis, kinetics and adsorption isotherms modeling. Bioresour. Technol. 2010, 101, 5070-5075. [CrossRef]

41. Ge, D.D.; You, Z.P.; Chen, S.Y.; Liu, C.C.; Gao, J.F.; Lv, S.T. The performance of asphalt binder with trichloroethylene: Improving the efficiency of using reclaimed asphalt pavement. J. Clean. Prod. 2019, 232, 205-212. [CrossRef]

42. Guan, R.L.; Li, X.J.; Wachemo, A.C.; Yuan, H.R.; Liu, Y.P.; Zou, D.X.; Zuo, X.Y.; Gu, J.Y. Enhancing anaerobic digestion performance and degradation of lignocellulosic components of rice straw by combined biological and chemical pretreatment. Sci. Total Environ. 2018, 637, 9-17. [CrossRef] [PubMed]

43. Nieves, D.C.; Karimi, K.; Horvath, I.S. Improvement of biogas production from oil palm empty fruit bunches (OPEFB). Ind. Crop. Prod. 2011, 34, 1097-1101. [CrossRef]

44. Xu, Z.Q.; Yuan, H.R.; Li, X.J. Anaerobic bioconversion efficiency of rice straw in continuously stirred tank reactor systems applying longer hydraulic retention time and higher load: One-stage vs. Two-stage. Bioresour. Technol. 2021, 321. [CrossRef]

45. Xu, X.J.; Wang, W.Q.; Chen, C.; Xie, P.; Liu, W.Z.; Zhou, X.; Wang, X.T.; Yuan, Y.; Wang, A.J.; Lee, D.J.; et al. Bioelectrochemical system for the enhancement of methane production by anaerobic digestion of alkaline pretreated sludge. Bioresour. Technol. 2020, 304, 9. [CrossRef] 
46. Sun, L.; Liu, T.; Muller, B.; Schnurer, A. The microbial community structure in industrial biogas plants influences the degradation rate of straw and cellulose in batch tests. Biotechnol. Biofuels 2016, 9, 20. [CrossRef]

47. Lanjekar, V.B.; Marathe, N.P.; Shouche, Y.S.; Ranade, D.R. Clostridium punense sp nov., an obligate anaerobe isolated from healthy human faeces. Int. J. Syst. Evol. Microbiol. 2015, 65, 4749-4756. [CrossRef]

48. Cho, H.U.; Kim, Y.M.; Park, J.M. Changes in microbial communities during volatile fatty acid production from cyanobacterial biomass harvested from a cyanobacterial bloom in a river. Chemosphere 2018, 202, 306-311. [CrossRef]

49. Bi, S.J.; Qiao, W.; Xiong, L.P.; Mandy, A.; Wandera, S.M.; Yin, D.M.; Dong, R.J. Improved high solid anaerobic digestion of chicken manure by moderate in situ ammonia stripping and its relation to metabolic pathway. Renew. Energy 2020, 146, 2380-2389. [CrossRef]

50. Zhao, Z.Q.; Wang, J.F.; Li, Y.; Zhu, T.T.; Yu, Q.L.; Wang, T.T.; Liang, S.; Zhang, Y.B. Why do DIETers like drinking: Metagenomic analysis for methane and energy metabolism during anaerobic digestion with ethanol. Water Res. 2020, 171, 14. [CrossRef] [PubMed]

51. Guan, R.; Yuan, H.; Zhang, L.; Zuo, X.; Li, X. Combined pretreatment using CaO and liquid fraction of digestate of rice straw: Anaerobic digestion performance and electron transfer. Chin. J. Chem. Eng. 2020. [CrossRef]

52. Ziganshina, E.E.; Belostotskiy, D.E.; Bulynina, S.S.; Ziganshin, A.M. Effect of magnetite on anaerobic digestion of distillers grains and beet pulp: Operation of reactors and microbial community dynamics. J. Biosci. Bioeng. 2021, 131, 290-298. [CrossRef]

53. Li, L.H.; He, S.B.; Sun, Y.M.; Kang, X.H.; Jiang, J.F.; Yuan, Z.H.; Liu, D.F. Anaerobic co-digestion of Pennisetum hybrid and pig manure: A comparative study of performance and microbial community at different mixture ratio and organic loading rate. Chemosphere 2020, 247, 10. [CrossRef]

54. Zhang, J.Y.; Wang, Z.Y.; Lu, T.D.; Liu, J.B.; Wang, Y.W.; Shen, P.H.; Wei, Y.S. Response and mechanisms of the performance and fate of antibiotic resistance genes to nano-magnetite during anaerobic digestion of swine manure. J. Hazard. Mater. 2019, 366, 192-201. [CrossRef] [PubMed]

55. Liu, X.; Wang, Q.; Tang, Y.; Pavlostathis, S.G. Hydrothermal pretreatment of sewage sludge for enhanced anaerobic digestion: Resource transformation and energy balance. Chem. Eng. J. 2021, 410, 127430. [CrossRef]

56. Guan, R.L.; Yuan, H.R.; Wachemo, A.C.; Li, X.J.; Zuo, X.Y.; Zou, D.X.; Liu, Y.P.; Gu, J.Y. Effect of Narrow Feeding Regimes on Anaerobic Digestion Performance and Microbial Community Structure of Rice Straw in Continuously Stirred Tank Reactors. Energy Fuels 2018, 32, 11587-11594. [CrossRef]

57. Sorokin, D.Y.; Toshchakov, S.V.; Kolganova, T.V.; Kublanov, I.V. Halo(natrono)archaea isolated from hypersaline lakes utilize cellulose and chitin as growth substrates. Front. Microbiol. 2015, 6. [CrossRef] [PubMed]

58. Bomberg, M.; Montonen, L.; Timonen, S. Anaerobic Eury- and Crenarchaeota inhabit ectomycorrhizas of boreal forest Scots pine. Eur. J. Soil Biol. 2010, 46, 356-364. [CrossRef]

59. Tejerizo, G.T.; Kim, Y.S.; Maus, I.; Wibberg, D.; Winkler, A.; Off, S.; Puhler, A.; Scherer, P.; Schluter, A. Genome sequence of Methanobacterium congolense strain Buetzberg, a hydrogenotrophic, methanogenic archaeon, isolated from a mesophilic industrial-scale biogas plant utilizing bio-waste. J. Biotechnol. 2017, 247, 1-5. [CrossRef] [PubMed]

60. Li, Y.; Achinas, S.; Zhao, J.; Geurkink, B.; Krooneman, J.; Willem Euverink, G.J. Co-digestion of cow and sheep manure: Performance evaluation and relative microbial activity. Renew. Energy 2020, 153, 553-563. [CrossRef]

61. Li, Y.; Zhao, J.; Achinas, S.; Zhang, Z.H.; Krooneman, J.; Euverink, G.J.W. The biomethanation of cow manure in a continuous anaerobic digester can be boosted via a bioaugmentation culture containing Bathyarchaeota. Sci. Total Environ. $2020,745$. [CrossRef] [PubMed]

62. Wei, Y.F.; Wachemo, A.C.; Yuan, H.R.; Li, X.J. Enhanced hydrolysis and acidification strategy for efficient co-digestion of pretreated corn stover with chicken manure: Digestion performance and microbial community structure. Sci. Total Environ. 2020, 720, 12. [CrossRef] [PubMed]

63. Evans, P.N.; Parks, D.H.; Chadwick, G.L.; Robbins, S.J.; Orphan, V.J.; Golding, S.D.; Tyson, G.W. Methane metabolism in the archaeal phylum Bathyarchaeota revealed by genome-centric metagenomics. Science 2015, 350, 434-438. [CrossRef] 